\title{
Gravitacijski separatori plin/kapljevina. Dio III.
}

DOI: $10.15255 /$ KUI.2015.004

KUI-28/2016

Stručni rad

Prispjelo 5. siječnja 2015.

Prihvaćeno 7. prosinca 2015.

\author{
E. Beer* \\ Aleja Blaža Jurišića 9, 10000 Zagreb
}

\begin{abstract}
|| Sažetak
Različiti postupci dimenzioniranja mogu se naći u literaturi. Više ih je za standardne tipove separatora. Za specifične izvedbe nema ih mnogo, obično su to postupci u kojima ima mnogo iskustvenih podataka i koje primjenjuju projektne organizacije, koje ih ne objavljuju. Ovdje su dani postupci za osam osnovnih tipova separatora: dva za dvofazne separatore i šest za trofazne. Postupci su dani s primjerima radi lakšeg razumijevanja postupka.
\end{abstract}

\| Ključne riječi

Gravitacijski separatori, separatori plin/kapljevina, separatori plin/kapljevina/kapljevina, dimenzioniranje

\section{Postupci proračuna i primjeri l.}

Relativno je malo publiciranih članaka s prikazom postupaka proračuna. Više ih je o dvofaznim separatorima plin/ kapljevina. U pravilu postupci su slični i razlikuju se samo u detaljima. Često je u postupak uključena optimalna izvedba posude s obzirom na cijenu, što je razumljivo jer se često radi o velikim posudama pod tlakom koje, iako u osnovi jednostavne konstrukcije, mogu biti skupe.

U sljedećim tablicama dane su preporuke vezane na konstrukciju posude i radne uvjete, što na neki način doprinosi optimalno dimenzioniranoj posudi.

Dane su formule za računanje debljine stijenki plašta i podnica ovisno o radnom tlaku i aproksimacije za površinu najčešće upotrebljavanih tipova podnica pomoću kojih se može procijeniti masa separatora.

Također su dane korelacije odnosa visine i površine kružnog odsječka koje su primijenjene pri proračunu vodoravnih separatora.

Dimenzioniranje se temelji na dva osnovna kriterija: potrebno zadržavanje kapljevite faze da se zadovolje zahtjevi procesa prije i poslije separatora i dovoljno dugo zadržavanje plinovite i kapljevite faze u separatoru da se stvore uvjeti koji će osigurati zahtijevano odvajanje plina od kapljevine i, kod trofaznih separatora, lakše kapljevine od teže kapljevine. U konačnici to se svodi na nalaženje promjera i duljine separatora s volumenom koji će zadovoljiti te kriterije.

Ima nekoliko iskustvenih pravila kojih se obično pridržava pri dimenzioniranju:

1. Maksimalna brzina izdvajanja kapljica dispergirane kapljevine iz kontinuirane faze druge kapljevine je $u_{\max }=0,255 \mathrm{~m} \mathrm{~min}^{-1}$ ili $0,00425 \mathrm{~m} \mathrm{~s}^{-1}$.

\footnotetext{
*Eduard Bee
}

e-pošta: eduard.beer@inet.hr
2. Brzina plina u parnom prostoru vodoravnog separatora u koji se ne ugrađuje odvajač kapljica izračunata je iz Souders-Brownova faktora podijeljenog s dva.

3. Minimalna potrebna visina parnog prostora za ugradnju odvajača kapljica u vodoravnim separatorima je $0,6 \mathrm{~m}$.

4. Ne računa se s volumenima podnica. Ti su volumeni na taj način dio sigurnosne margine.

Postupci koji se navode ne uključuju optimizaciju iako se preporučuje npr. najpovoljniji omjer duljina/promjer ovisno o radnom tlaku ili izboru vrste podnice.

Prikazani su postupci s primjerima što će po mom mišljenju olakšati praćenje postupka.

Neki dijelovi proračuna, priključci, pad tlaka, isti su za sve tipove separatora. Da se ne ponavljaju u svim primjerima, detaljan proračun dan je u prvom primjeru, dok su u ostalim primjerima dani samo konačni rezultati.

Napomena: Primjeri su računati programom na računalu, a rezultati prikazani u tekstu su zaokružene vrijednosti. Račun s tako zaokruženim brojevima ne mora se u decimalama slagati s rezultatima danim u tekstu.

Tablica 27 - Preporuke za omjer L/D

Table 27 - Recommended L/D ratio

\begin{tabular}{c|c}
$\begin{array}{c}\text { Radni tlak/bar } \\
\text { Operating pressure /bar }\end{array}$ & $L / D$ \\
$0<p \leq 15$ & $1,5-3,0$ \\
$15<p<35$ & $3,0-4,0$ \\
$p>35$ & $4,0-6,0$
\end{tabular}


Tablica 28 - Preporučene minimalne visine niskog nivoa kapljevine

Table 28 - Recommended minimum height for low liquid level

\begin{tabular}{|c|c|c|c|}
\hline \multirow{3}{*}{$\begin{array}{l}\text { Promjer } \\
\text { posude } / \mathrm{mm} \\
\text { Drum } \\
\text { diameter } / \mathrm{mm}\end{array}$} & \multirow{2}{*}{\multicolumn{2}{|c|}{$\begin{array}{c}\text { Okomita posuda } \\
\text { Vertical drum } \\
(\mathrm{T} / \mathrm{L}-\mathrm{LLL}) / \mathrm{mm} \\
\text { apsolutni radni tlak } \\
\text { absolute operating pressure }\end{array}$}} & \multirow{3}{*}{$\begin{array}{l}\text { Vodoravna posuda } \\
\text { Horizontal drum } \\
\text { LLL/mm }\end{array}$} \\
\hline & & & \\
\hline & $<20$ bar & $>20$ bar & \\
\hline$\leq 1200$ & 380 & 150 & 230 \\
\hline 1800 & 380 & 150 & 250 \\
\hline 2400 & 380 & 150 & 275 \\
\hline 3000 & 150 & 150 & 300 \\
\hline 3600 & 150 & 150 & 330 \\
\hline 4900 & 150 & 150 & 380 \\
\hline
\end{tabular}

Tablica 29 - Preporuke za izbor tipa podnice

Table 29 - Recommended head type

\begin{tabular}{l|c|c}
\hline $\begin{array}{l}\text { Tip podnice } \\
\text { Head type }\end{array}$ & $\begin{array}{c}\text { Promjer posude } / \mathrm{mm} \\
\text { Drum diameter } / \mathrm{mm}\end{array}$ & $\begin{array}{c}\text { Radni tlak/bar } \\
\text { Operating } \\
\text { pressure } / \text { bar }\end{array}$ \\
\hline $\begin{array}{l}2: 1 \text { eliptična } \\
2: 1 \text { elliptical head }\end{array}$ & $<4500$ & $>7$ \\
$\begin{array}{l}\text { hemisfera } \\
\text { hemispherical head }\end{array}$ & $>4500$ & - \\
$\begin{array}{l}\text { torisferična, } r=0,6 \mathrm{D} \\
\text { dished head, } r=0,6 \mathrm{D}\end{array}$ & $<4500$ & $<7$ \\
\hline
\end{tabular}

Tablica 30 - Odnosi visine $(H)$ i površine $(A)$ kružnog odsječka Table 30 - Segment height and area conversions

\begin{tabular}{c|cc}
\hline & \multicolumn{2}{|c}{$Y=\frac{a+c X+g X^{2}+i X^{3}}{1,0+b X+d X^{2}+f X^{3}+h X^{4}}$} \\
\cline { 2 - 3 } & $X=\frac{H}{D} ; Y=\frac{A}{A_{t}}$ & $X=\frac{A}{A_{t}} ; Y=\frac{H}{D}$ \\
\hline a & $-4,755930 \cdot 10^{-5}$ & 0,00153756 \\
b & 3,924091 & 26,787101 \\
c & 0,174875 & 3,299201 \\
d & $-6,358805$ & $-22,923932$ \\
e & 5,668973 & 24,353518 \\
f & 4,018448 & $-14,844824$ \\
g & $-4,916411$ & $-36,999376$ \\
h & $-1,801705$ & 10,529572 \\
i & $-0,145348$ & 9,892851
\end{tabular}

$H$ - visina odsječka / segment height $D$ - promjer kruga / circle diameter

$A$ - površina odsječka / segment area

$A_{\mathrm{t}}$ - površina kruga / circle area

\section{Dvofazni VL-separatori}

Dva su osnovna tipa dvofaznih gravitacijskih separatora, okomiti i vodoravni. Daljnje razlike su samo u detaljima: tipovi ugrađenih raspodjelnika i tipovi odvajača kapljica ili bez odvajača kapljica.

Izbor između okomitog i vodoravnog separatora ovisi o omjeru plina prema kapljevini u smjesi.

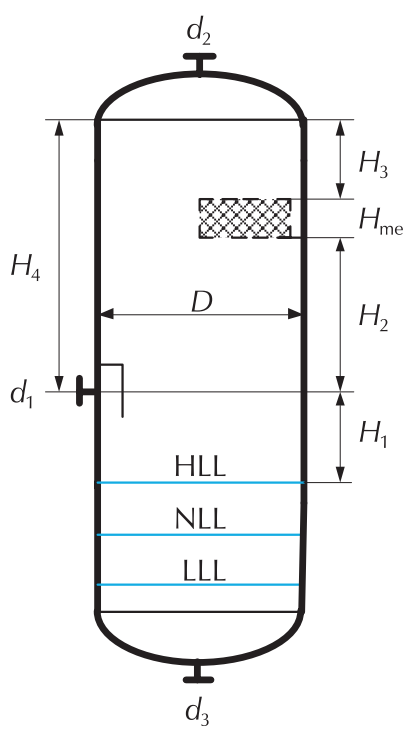

a) okomiti vertical

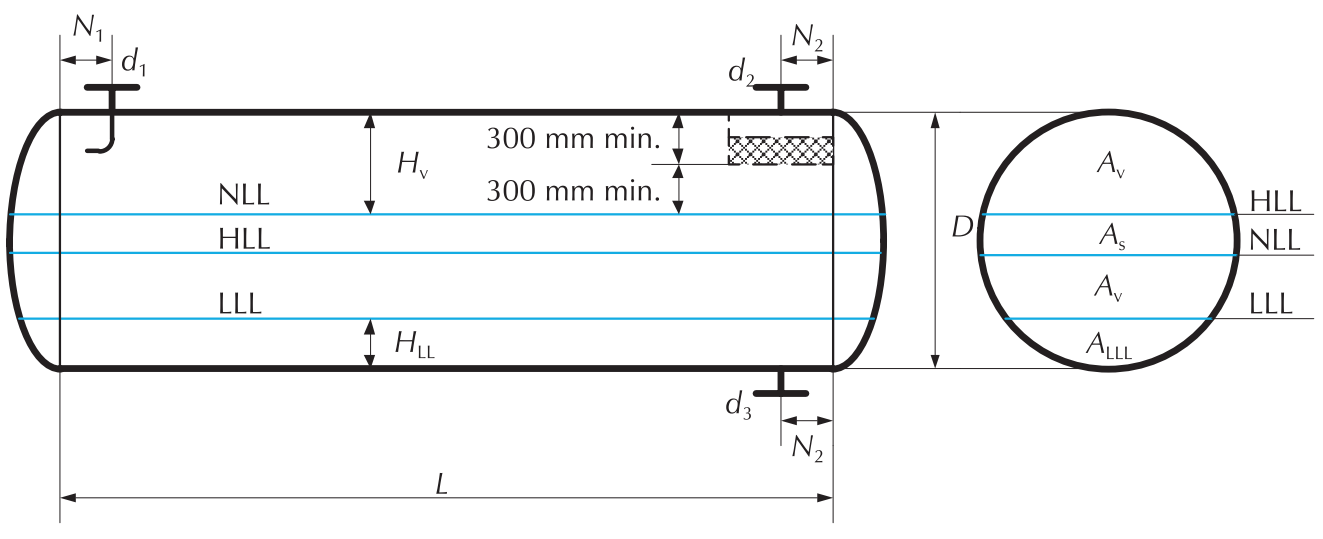

b) vodoravni

horizontal

Slika 23 - Dvofazni V/L S-separatori

Fig. 23 - Two phase V/L separators 
Ako je protok kapljevine u odnosu na protok plina mali $(<10-20 \%$ mase), uzima se okomiti separator. Hoće li se ugraditi odvajač kapljica ili ne ovisi o zahtjevu procesa nakon separatora. Na primjer KO-posuda prije baklje uvijek je separator bez odvajača kapljica.

\section{Primjer 1. Okomiti VL-separator (slika 23a)}

Proračun se temelji na projektnoj brzini plina u separatoru. Brzina plina računa se ovisno o tome ugrađuje li se odvajač kapljica ili ne. Unutarnji promjer separatora zadan je brzinom i volumnim protokom plina.

Visine sekcija u parnom prostoru iskustveni su podatci, a visine razine kapljevine računaju se na temelju vremena zadržavanja i poremećaja.

Ne računa se s volumenom donje podnice. Taj je volumen neka vrsta sigurnosne margine.

\section{Podatci za proračun}

Treba načiniti proračun dvofaznog separatora za odvajanje plinsko-kapljevite smjese sljedećih karakteristika:

protok plina, $Q_{\mathrm{vG}}=1000 \mathrm{~m}^{3} \mathrm{~h}^{-1}=0,278 \mathrm{~m}^{3} \mathrm{~s}^{-1}$ gustoća plina, $\rho_{\mathrm{G}}=25 \mathrm{~kg} \mathrm{~m}^{-3}$

viskoznost plina, $\mu_{\mathrm{G}}=0,0125 \mathrm{mPa} \mathrm{s}$

protok kapljevine, $Q_{\mathrm{vL}}=5 \mathrm{~m}^{3} \mathrm{~h}^{-1}=0,00139 \mathrm{~m}^{3} \mathrm{~s}^{-1}$

gustoća kapljevine, $\rho_{\mathrm{L}}=625 \mathrm{~kg} \mathrm{~m}^{-3}$

granični promjer kapljice koja se odvaja iz plina,

$D_{\mathrm{p}}=100 \mathrm{~mm}$

radni tlak separatora, $p=25$ bar

u separator se ugrađuje odvajač kapljica

distributor ulazne smjese je poluotvorena cijev

vrijeme zadržavanja, $t_{\mathrm{h}}=5 \mathrm{~min}=300 \mathrm{~s}$

vrijeme poremećaja, $t_{\mathrm{s}}=2 \mathrm{~min}=120 \mathrm{~s}$

sigurnosna margina/sigurnosni faktor, $F_{\mathrm{s}}=1,15$

U proračunu svi protoci su množeni sa sigurnosnim faktorom!

\section{Souders-Brownov K-faktor i granična brzina plina}

U separator će biti ugrađen odvajač kapljica od čelične mrežice. Souders-Brownov $K$-faktor računamo korelacijama za odvajače iz mrežice (Koch-Otto York) za apsolutni radni tlak $p>2,75$ bar (jedn. 33):

$$
\begin{aligned}
K & =[0,1123-0,007 \ln (p / \text { bar })] \mathrm{ms}^{-1} \\
& =[0,1123-0,007 \ln (26,013)] \mathrm{ms}^{-1}=0,0895 \mathrm{~ms}^{-1}
\end{aligned}
$$

Granična brzina plina iz jedn. 14:

$$
u_{\mathrm{t}}=K \sqrt{\frac{\rho_{\mathrm{L}}-\rho_{\mathrm{G}}}{\rho_{\mathrm{G}}}}=0,0895 \sqrt{\frac{625-25}{25}} \mathrm{~ms}^{-1}=0,438 \mathrm{~ms}^{-1}
$$

Projektna brzina:

$$
u_{\mathrm{d}}=\frac{u_{\mathrm{t}}}{F_{\mathrm{s}}}=\frac{0,438}{1,15} \mathrm{~ms}^{-1}=0,381 \mathrm{~ms}^{-1}
$$

\section{Promjer separatora}

$$
D_{\mathrm{i}}=\left(\frac{4 Q_{\mathrm{vG}}}{\pi u_{\mathrm{d}}}\right)^{1 / 2}=\left(\frac{4 \cdot 0,319}{\pi \cdot 0,381}\right)^{1 / 2} \mathrm{~m}=1,033 \mathrm{~m}
$$

Ako se ugrađuje odvajač kapljica, tada promjeru treba dodati širinu prstena nosača odvajača kapljica. Širina prstena $t_{\text {nok }}=50 \mathrm{~mm}$

$$
D_{\mathrm{i}}=D_{\mathrm{i}}+2 \cdot t_{\text {nok }}=(1,033+2 \cdot 0,05) \mathrm{m}=1,133 \mathrm{~m}
$$

Zaokružimo: $D_{\mathrm{i}}=1,135 \mathrm{~m}=1135 \mathrm{~mm}$

\section{Volumen zadržavanja i volumen poremećaja kapljevite faze u separatoru}

Volumen zadržavanja, $t_{\mathrm{h}}=5 \mathrm{~min}$ :

$$
V_{\mathrm{h}}=t_{\mathrm{h}} Q_{\mathrm{vL}}=300 \cdot 0,001660 \mathrm{~m}^{3}=0,479 \mathrm{~m}^{3}
$$

Volumen poremećaja, $t_{\mathrm{s}}=2 \mathrm{~min}$ :

$$
V_{\mathrm{s}}=t_{\mathrm{s}} Q_{\mathrm{vL}}=120 \cdot 0,001660 \mathrm{~m}^{3}=0,192 \mathrm{~m}^{3}
$$

\section{Visine nivoa kapljevine: LLL, NLL $i$ HLL}

Iz tablice 28 za separatore na apsolutnom radnom tlaku od $p>20$ bar, bez obzira na promjer, preporučena visina LLL iznad T/L je $150 \mathrm{~mm}$. $U$ našem primjeru $p=25$ bar i uzimamo:

$$
\mathrm{LLL}=0,150 \mathrm{~m}
$$

Visina volumena zadržavanja:

$$
H_{\mathrm{h}}=\frac{V_{\mathrm{h}}}{\frac{D_{\mathrm{i}}^{2} \cdot \pi}{4}}=\frac{0,479}{\frac{1,135^{2} \cdot \pi}{4}} \mathrm{~m}=0,474 \mathrm{~m}
$$

Visina je veća od $300 \mathrm{~mm}$, pa nema potrebe za korekcijom.

Visina volumena poremećaja

$$
H_{\mathrm{s}}=\frac{V_{\mathrm{s}}}{\frac{D_{\mathrm{i}}^{2} \cdot \pi}{4}}=\frac{0,192}{\frac{1,135^{2} \cdot \pi}{4}} \mathrm{~m}=0,474 \mathrm{~m}
$$

Visina je veća od $150 \mathrm{~mm}$, pa nema potrebe za korekcijom.

Visine iznad $\mathrm{T} / \mathrm{L}$ dna:

$\mathrm{LLL}=0,150 \mathrm{~m}$

$N L L=0,150 m+0,474 m=0,624 m$

(zaokruženo na 0,625 m)

$\mathrm{HLL}=0,624 \mathrm{~m}+0,189 \mathrm{~m}=0,813 \mathrm{~m}$

(zaokruženo na 0,815 m) 


\section{Dimenzije priključaka}

Maksimalna i minimalna brzina smjese u ulaznom priključ$\mathrm{ku}^{9}$ iz jedn. 49, 50, 52 i 53:

$$
\begin{aligned}
Q_{\mathrm{vM}} & =Q_{\mathrm{vG}}+Q_{\mathrm{vL}}=0,319 \mathrm{~m}^{3} \mathrm{~s}^{-1}+0,00160 \mathrm{~m}^{3} \mathrm{~s}^{-1} \\
& =0,321 \mathrm{~m}^{3} \mathrm{~s}^{-1} \\
x & =\frac{Q_{\mathrm{vL}}}{Q_{\mathrm{vL}}+Q_{\mathrm{vG}}}=\frac{0,00160}{0,00160+0,319}=0,004975 \\
\rho_{\mathrm{M}} & =\rho_{\mathrm{L}} x+\rho_{\mathrm{G}}(1-x) \\
& =625 \cdot 0,004975+25(1-0,004975) \mathrm{kg} \mathrm{m}^{-3} \\
& =27,985 \mathrm{~kg} \mathrm{~m}^{-3} \\
\left(u_{\max }\right)_{\text {priklj }} & =\frac{122}{\sqrt{\rho_{\mathrm{M}} / \mathrm{kg} \mathrm{m}^{-3}}} \mathrm{~m} \mathrm{~s}^{-1} \\
& =\frac{122}{\sqrt{27,985}} \mathrm{~m} \mathrm{~s}^{-1}=23,062 \mathrm{~m} \mathrm{~s}^{-1} \\
\left(u_{\min }\right)_{\text {priklj }} & =\frac{73,2}{\sqrt{\rho_{\mathrm{M}} / \mathrm{kg} \mathrm{m}^{-3}}} \mathrm{~m} \mathrm{~s}^{-1} \\
& =\frac{73,2}{\sqrt{27,985}} \mathrm{~m} \mathrm{~s}^{-1}=13,837 \mathrm{~m} \mathrm{~s}^{-1}
\end{aligned}
$$

Prema kriteriju Shell GS/6 moment sile, ako je raspodjelnik poluotvorena cijev, biti (jedn. 58):

$$
\rho_{\mathrm{M}} u_{\mathrm{M}}^{2} \leq 2100 \mathrm{~Pa}
$$

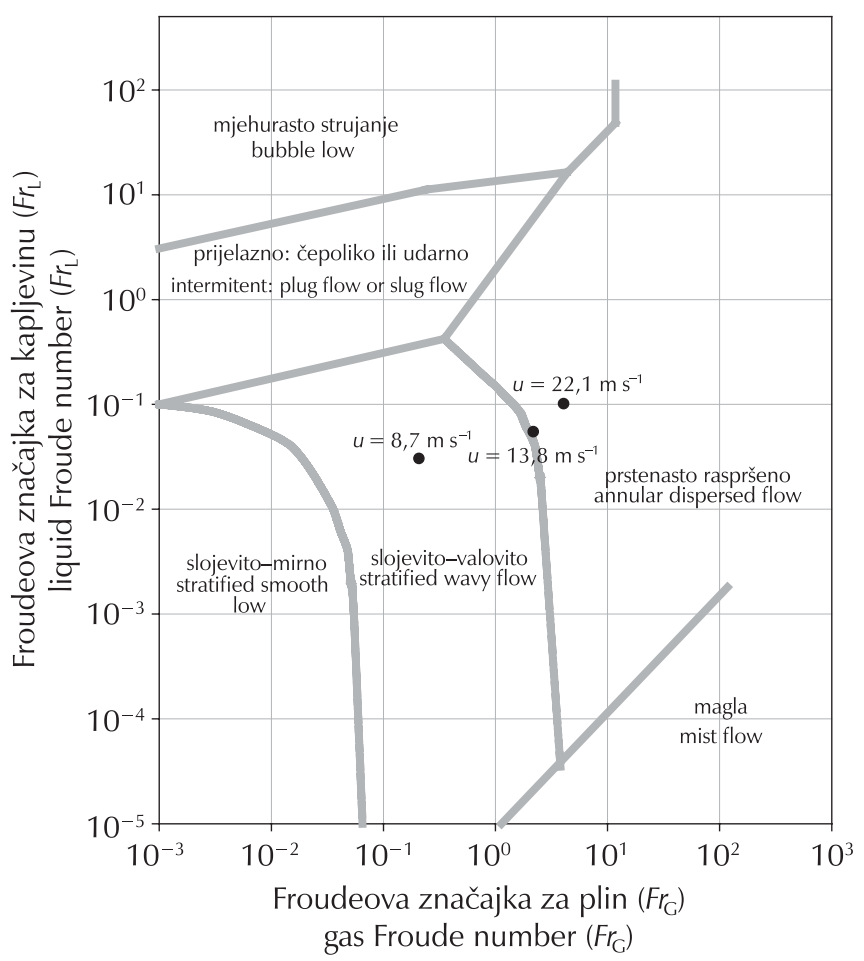

Slika 24a - Oblik strujanja: vodoravna cijev

Fig. 24a - Flow regime: horizontal pipe
Odnosno brzina je:

$$
u_{\max }=\sqrt{\frac{2100 \mathrm{~Pa}}{\rho_{\mathrm{M}}}}=\sqrt{\frac{2100 \mathrm{~Pa}}{27,985 \mathrm{~kg} \mathrm{~m}^{-3}}}=8,662 \mathrm{~m} \mathrm{~s}^{-1}
$$

To su značajne razlike. Minimalna brzina prema Watkinsu, s kojom računaju i Monnery i Svrcek je za 60 \% veća od maksimalne brzine prema kriteriju Shell GSI.

Načinit ćemo kontrolu oblika strujanja. Proračun Froudeove značajke za te tri brzine daje:

\begin{tabular}{c|c|c|c|}
\hline \multirow{2}{*}{} & \multicolumn{3}{|c}{$u / \mathrm{ms}^{-1}$} \\
\cline { 2 - 4 } & 22,062 & 13,837 & 8,662 \\
\hline$F r_{\mathrm{G}}$ & 4,11 & 2,165 & 1,206 \\
$F r_{\mathrm{L}}$ & 0,102 & 0,0541 & 0,0301 \\
\hline
\end{tabular}

Uneseno u grafove na slikama 17 i 18 dobijemo radne točke na slikama 24a i $24 \mathrm{~b}$.

Brzine, maksimalna i minimalna po Watkinsu, daju prstenasto-raspršeno strujanje. Brzina prema kriteriju momenta sile daje slojevito-valovito strujanje u vodoravnoj cijevi i radnu točku na granici prijelaznog i prstenasto-raspršenog strujanja u okomitoj cijevi.

U oba slučaja maksimalna brzina prema kriteriju momenta sile povoljnija je i uzimamo da je brzina u ulaznom priključku $u=8,7 \mathrm{~m} \mathrm{~s}^{-1}$.

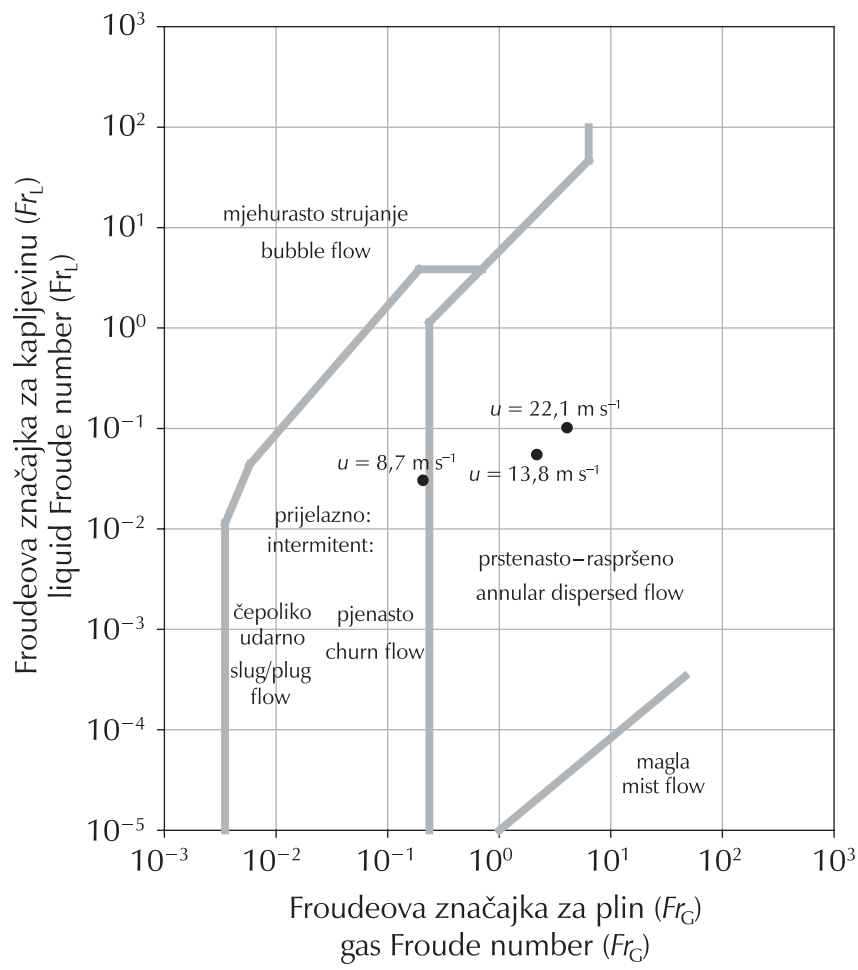

Slika $24 b$ - Oblik strujanja: okomita cijev Fig. $24 b$ - Flow regime: vertical pipe (upflow) 
Unutarnji promjer ulaznog priključka:

$$
d_{1}=\sqrt{\frac{4 Q_{v M}}{\pi u}}=\sqrt{\frac{4 \cdot 0,321 \mathrm{~m}^{3} \mathrm{~s}^{-1}}{\pi \cdot 8,7 \mathrm{~m} \mathrm{~s}^{-1}}}=0,217 \mathrm{~m}=217 \mathrm{~mm}
$$

Prvi veći standardni promjer cijevi je 10" Sch 40 vanjskog promjera $d_{0}=273,05 \mathrm{~mm}$ i unutarnjeg promjera $d_{\mathrm{i}}=254,51 \mathrm{~mm}$.

Za odvod plina uzimamo priključak 8" Sch 40 vanjskog promjera $219,07 \mathrm{~mm}$ i unutarnjeg promjera $202,72 \mathrm{~mm}$.

Priključak za odvod kapljevine. Računamo s brzinom kapljevine $u=1 \mathrm{~m} \mathrm{~s}^{-1}$ :

$$
d_{3}=\sqrt{\frac{4 Q_{\mathrm{vL}}}{\pi u}}=\sqrt{\frac{4 \cdot 0,00160 \mathrm{~m}^{3} \mathrm{~s}^{-1}}{\pi \cdot 1,0 \mathrm{~m} \mathrm{~s}^{-1}}}=0,045 \mathrm{~m}=45 \mathrm{~mm}
$$

Uzimamo cijev nazivnog promjera 2" Sch 40, unutarnjeg promjera $52,50 \mathrm{~mm}$.

\section{Visine parnog prostora}

Prema tablici 20 za okomiti separator s distributorom od polucijevi i ugrađenim odvajačem kapljica od žičane mrežice preporučene su visine parnog prostora za poluotvorenu cijev:

\begin{tabular}{c|c|c|c}
\hline$H_{1}$ & $H_{2}$ & $H_{3}$ & Visina \\
\hline $0,3 \mathrm{D}$ & $0,45 \mathrm{D}$ & $0,15 \mathrm{D}$ & \\
$\min .300 \mathrm{~mm}$ & $\min .600 \mathrm{~mm}$ & $\min .150 \mathrm{~mm}$ & $\mathrm{~d}_{1}$ \\
\hline
\end{tabular}

$$
\begin{aligned}
D_{\mathrm{i}}= & 1135 \mathrm{~mm} \\
H_{1}= & 0,3 \cdot 1135 \mathrm{~mm}=340,5 \mathrm{~mm} \\
& \text { zaokruženo na } H_{1}=340 \mathrm{~mm} \\
H_{2}= & 0,45 \cdot 1135 \mathrm{~mm}=510,75 \mathrm{~mm} \\
& \text { minimum je } 600 \mathrm{~mm}, \text { stoga } H_{2}=600 \mathrm{~mm} \\
H_{3}= & 0,15 \cdot 1135 \mathrm{~mm}=170,25 \mathrm{~mm} ; \\
& \text { zaokruženo na } H_{3}=170 \mathrm{~mm} \\
d_{1}= & 273,1 \mathrm{~mm}
\end{aligned}
$$

\section{Dimenzije separatora}

\begin{tabular}{l|r}
\hline$D i$ & $1135 \mathrm{~mm}$ \\
$H_{1}$ & $170 \mathrm{~mm}$ \\
$H_{2}$ & $600 \mathrm{~mm}$ \\
$H_{3}$ & $170 \mathrm{~mm}$ \\
$H$, odvajač kapljica & $150 \mathrm{~mm}$ \\
$d_{1}$ & $273 \mathrm{~mm}$ \\
$H$, ukupno (T/L) & $2348 \mathrm{~mm}$ \\
\hline
\end{tabular}

\begin{tabular}{l|c}
\hline LLL & $150 \mathrm{~mm}$ \\
NLL & $625 \mathrm{~mm}$ \\
HLL & $815 \mathrm{~mm}$ \\
L/D & 2,069 \\
\hline \multicolumn{2}{c}{} \\
\hline ulaz smjese & priključci \\
izlaz plina & 8" Sch 40 \\
izlaz kapljevine 40 \\
\hline
\end{tabular}

\section{Pad tlaka}

Pad tlaka kroz ulazni priključak:

$$
\begin{aligned}
u_{M} & =\frac{4 Q_{v M}}{\pi d_{1}^{2}}=\frac{4 \cdot 0,321 \mathrm{~m}^{3} \mathrm{~s}^{-1}}{\pi \cdot(0,2545 \mathrm{~m})^{2}}=6,331 \mathrm{~m} \mathrm{~s}^{-1} \\
\Delta p_{\mathrm{d}_{1}} & =0,5 \rho_{\mathrm{M}} \cdot u_{\mathrm{M}, \mathrm{in}}^{2} \\
& =0,5 \cdot 27,985 \mathrm{~kg} \mathrm{~m}^{-3} \cdot\left(6,331 \mathrm{~m} \mathrm{~s}^{-1}\right)^{2}=561 \mathrm{~Pa}
\end{aligned}
$$

Pad tlaka kroz priključak za izlaz plina:

$$
\Delta p_{\mathrm{d}_{2}}=542 \mathrm{~Pa}
$$

Pad tlaka kroz odvajač kapljica.

Nije specificirano koji je tip odvajača i kako je postavljen, pa je dan proračun za žičanu mrežicu i pločaste izdvajače kapljica. Pad tlaka dan je za površinu odvajača od $1 \mathrm{~m}^{2}$ jer površina presjeka protoka plina ovisi o tipu i načinu postavljanja odvajača kapljica.

$$
\begin{aligned}
\lambda & =\frac{Q_{\mathrm{vG}}}{A_{\mathrm{s}, \mathrm{me}}} \sqrt{\frac{\rho_{\mathrm{G}}}{\rho_{\mathrm{L}}-\rho_{\mathrm{G}}}} \\
& =\frac{0,319 \mathrm{~m}^{3} \mathrm{~s}^{-1}}{1,0 \mathrm{~m}^{2}} \sqrt{\frac{25}{625-25}}=0,0651 \mathrm{~m} \mathrm{~s}^{-1}
\end{aligned}
$$

Pad tlaka kroz žičanu mrežicu na $1 \mathrm{~m}^{2}$ (jedn. 23 i 24):

$$
\begin{aligned}
\Delta p & =200 \frac{\rho_{\mathrm{L}}-\rho_{\mathrm{G}}}{\mathrm{kg} \mathrm{m}^{-3}} \cdot \frac{\lambda^{2}}{\mathrm{~m}^{2} \mathrm{~s}^{-2}} \cdot \frac{t_{\mathrm{me}}}{\mathrm{m}} \mathrm{Pa} \\
& =200(625-25) \cdot 0,0651^{2} \cdot 0,150 \mathrm{~Pa}=76,3 \mathrm{~Pa}
\end{aligned}
$$

ili

$$
\begin{aligned}
\Delta p & =20000 \frac{\lambda^{2}}{\mathrm{~m}^{2} \mathrm{~s}^{-2}} \cdot \frac{t_{\mathrm{me}}}{\mathrm{m}} \mathrm{mm} \\
& =20000 \cdot 0,0651^{2} \cdot 0,150=12,7 \mathrm{~mm} \\
& \text { (visina stupca procesne kapljevine) }
\end{aligned}
$$


Pad tlaka kroz pločasti odvajač (jedn. 26) na $1 \mathrm{~m}^{2}$. Dvostruki džepovi:

$$
\begin{aligned}
\Delta p & =K_{\mathrm{v}}\left(\rho_{\mathrm{L}}-\rho_{\mathrm{C}}\right) \lambda^{2} \\
& =15(625-25) \mathrm{kg} \mathrm{m}^{-3} \cdot\left(0,06512 \mathrm{~m} \mathrm{~s}^{-1}\right)^{2}=37,4 \mathrm{~Pa}
\end{aligned}
$$

Jednostruki džepovi:

$$
\begin{aligned}
\Delta p & =K_{\mathrm{v}}\left(\rho_{\mathrm{L}}-\rho_{\mathrm{G}}\right) \lambda^{2} \\
& =10(625-25) \mathrm{kg} \mathrm{m}^{-3} \cdot\left(0,06512 \mathrm{~m} \mathrm{~s}^{-1}\right)^{2}=24,9 \mathrm{~Pa}
\end{aligned}
$$

\section{Primjer 2. Vodoravni VL-separator (slika 23b)}

Promjer i duljina separatora ovise o protoku plina i graničnoj brzini izdvajanja kapljica te o volumenima zadržavanja i vremenu poremećaja, stoga je postupak iterativan dok se ne usklade svi zahtjevi. Počinje s pretpostavkom da je $60 \%$ površine presjeka zauzeto volumenima zadržavanja i poremećaja, $A_{\mathrm{h}}$ i $A_{\mathrm{s}}$. Uz odabranu visinu LLL i omjer duljine i promjera separatora izračunava se unutarnji promjer i kontrolira jesu li zadovoljeni uvjeti: vodoravna brzina plina i volumeni zadržavanja i poremećaja. Ako neki od uvjeta nije zadovoljen, mijenja se promjer ili duljina dok se ne dobije zadovoljavajuće rješenje.

Često se u literaturi može naći da se visina parnog prostora ograničava ovisno o tome hoće li biti ugrađen odvajač kapljica ili ne, pa se za slučaj ugradnje odvajača kapljica kao minimalna visina parnog prostora preporučuje $600 \mathrm{~mm}$. To ne mora uvijek biti potrebno. Ovisno o tipu odvajača kapljica i načinu ugradnje (vodoravan ili okomit) te o protoku plina može biti dovoljno i $300 \mathrm{~mm}$ visine parnog prostora. Stoga je preporuka da se načini dimenzioniranje separatora i tada odabere odvajač kapljica i način ugradnje.

Kao i kod okomitog separatora ne računa se s volumenima podnica. Njihovi su volumeni neka vrsta sigurnosne margine.

$\mathrm{U}$ ovom primjeru načinit će se proračun $\mathrm{KO}$-posude baklje. Za te KO-posude zahtjev je da su vodoravni separatori bez odvajača kapljica.

\section{Podatci za proračun}

protok plina, $Q_{v G}=26500 \mathrm{~m}^{3} \mathrm{~h}^{-1}=7,361 \mathrm{~m}^{3} \mathrm{~s}^{-1}$

gustoća plina, $\rho_{\mathrm{G}}=2,9 \mathrm{~kg} \mathrm{~m}^{-3}$

viskoznost plina, $\mu_{\mathrm{G}}=0,01 \mathrm{mPa} \mathrm{s}$

protok kapljevine, $Q_{\mathrm{vL}}=28,5 \mathrm{~m}^{3} \mathrm{~h}^{-1}=0,00792 \mathrm{~m}^{3} \mathrm{~s}^{-1}$

gustoća kapljevine, $\rho_{\mathrm{L}}=496,6 \mathrm{~kg} \mathrm{~m}^{-3}$

granični promjer kapljice koja se odvaja iz plina,

$D_{\mathrm{p}}=300 \mu \mathrm{m}$

apsolutni radni tlak separatora, $p=1,013$ bar

distributor ulazne smjese je koljeno dugog polumjera

vrijeme zadržavanja, $t_{\mathrm{h}}=4 \mathrm{~min}$

vrijeme poremećaja, $t_{\mathrm{s}}=30 \mathrm{~min}$

sigurnosna margina/sigurnosni faktor, $F_{\mathrm{s}}=1,0$
Za KO-posude sustava baklje karakteristično je da je vrijeme zadržavanja kraće od vremena poremećaja. Vrijeme poremećaja je vrijeme aktiviranja sigurnosnih ventila, dok je vrijeme zadržavanja određeno volumenom drenaža i "slopa".

\section{Granična brzina plina}

Graničnu brzinu plina računamo iz teorijske korelacije bez očitanja iz slike 2 (jedn. 8, 15, 36, 37).

$$
\begin{aligned}
C_{\mathrm{D}} \operatorname{Re}^{2}= & \frac{1,31 \cdot 10^{7} \rho_{\mathrm{G}} \cdot D_{\mathrm{p}}^{3} \cdot\left(\rho_{\mathrm{L}}-\rho_{\mathrm{C}}\right)}{\mu_{\mathrm{G}}^{2}} \\
\quad= & \frac{1,31 \cdot 10^{-7} \cdot 2,9 \cdot 0,0003^{3}(496,6-2,9)}{0,01^{2}}=5064,03 \\
X= & C_{\mathrm{D}} \operatorname{Re}^{2} \\
C_{\mathrm{D}}= & 0,344+3,079 \cdot 10^{-8} X+\frac{64,91}{X^{0,5}}+\frac{3514,81}{X^{1,5}}-\frac{7201,95}{X^{2}} \\
= & 0,344+3,079 \cdot 10^{-8} \cdot 5064,03+ \\
& +\frac{64,91}{5064,03^{0,5}}+\frac{3514,81}{5064,03^{1,5}}-\frac{7201,95}{5064,03^{2}} \\
= & 1,266
\end{aligned}
$$

$K=\sqrt{\frac{4 g D_{\mathrm{p}}}{3 C_{\mathrm{D}}}}=\sqrt{\frac{4 \cdot 9,806 \cdot 0,0003}{3 \cdot 1,266}} \mathrm{~m} \mathrm{~s}^{-1}=0,056 \mathrm{~m} \mathrm{~s}^{-1}$

Granična brzina plina iz jedn. 15:

$$
u_{\mathrm{t}}=K \sqrt{\frac{\rho_{\mathrm{L}}-\rho_{\mathrm{G}}}{\rho_{\mathrm{G}}}}=0,056 \sqrt{\frac{496,6-2,9}{2,9}} \mathrm{~ms}^{-1}=0,726 \mathrm{~ms}^{-1}
$$

\section{Volumen zadržavanja i volumen poremećaja kapljevite faze u separatoru}

Volumen zadržavanja, $t_{\mathrm{h}}=4 \mathrm{~min}$ :

$$
V_{\mathrm{h}}=t_{\mathrm{h}} \cdot Q_{\mathrm{vL}}=240 \mathrm{~s} \cdot 0,00792 \mathrm{~m}^{3} \mathrm{~s}^{-1}=1,9 \mathrm{~m}^{3}
$$

Volumen poremećaja, $t_{\mathrm{s}}=30 \mathrm{~min}$ :

$$
V_{\mathrm{s}}=t_{\mathrm{s}} \cdot Q_{\mathrm{vL}}=1800 \mathrm{~s} \cdot 0,00792 \mathrm{~m}^{3} \mathrm{~s}^{-1}=14,25 \mathrm{~m}^{3}
$$

\section{Promjer separatora}

Za radni tlak do $p=15$ bar preporučeni omjer $L / D$ iz tablice 27 je između 1,5 i 3. Uzimamo $L / D=2,5$.

Preliminarni promjer separatora iz volumena zadržavanja i volumena poremećaja:

$$
D_{\mathrm{i}}=\left[\frac{4\left(V_{\mathrm{h}}+V_{\mathrm{s}}\right)}{0,6 \pi \frac{L}{D}}\right]^{1 / 3}=\left[\frac{4(1,9+14,25) \mathrm{m}^{3}}{0,6 \pi \cdot 2,5}\right]^{1 / 3}=2,393 \mathrm{~m}
$$

Zaokružimo: $D_{\mathrm{i}}=2,400 \mathrm{~m}$. 
Površina presjeka separatora:

$$
A_{\mathrm{t}}=\frac{D_{\mathrm{i}}^{2} \pi}{4}=\frac{(2,4 \mathrm{~m})^{2} \pi}{4}=4,524 \mathrm{~m}^{2}
$$

\section{Visina i površina parnog prostora}

Protok plinova je relativno velik i kao početnu veličinu uzimamo da je visina parnog prostora 0,4D.

$$
\begin{gathered}
H_{\mathrm{v}}=0,4 \cdot 2,4 \mathrm{~m}=0,96 \mathrm{~m} \\
X=0,4
\end{gathered}
$$

Iz korelacije u tablici 31: $Y=0,3735$;

$$
A_{v}=Y \cdot A_{\mathrm{t}}=0,3735 \cdot 4,524 \mathrm{~m}^{2}=1,69 \mathrm{~m}^{2} .
$$

\section{Visina LLL i površina presjeka $A_{\text {LLL }}$}

Iz tablice 28 preporučena visina parnog prostora za vodoravnu posudu promjera $D=2,4 \mathrm{~m}$; $L L L=275 \mathrm{~mm}$.

$$
X=\frac{H_{\mathrm{v}}}{D_{\mathrm{i}}}=\frac{0,275 \mathrm{~m}}{2,400 \mathrm{~m}}=0,1146
$$

Iz korelacije u tablici 31: $Y=0,06342$;

$$
A_{\mathrm{LLL}}=Y \cdot A_{\mathrm{t}}=0,06342 \cdot 4,524 \mathrm{~m}^{2}=0,287 \mathrm{~m}^{2} .
$$

\section{Duljina separatora koja zadovoljava vremena zadržaja i poremećaja}

$$
\begin{aligned}
L_{\mathrm{H} / \mathrm{S}} & =\frac{V_{\mathrm{h}}+V_{\mathrm{S}}}{A_{\mathrm{t}}-A_{\mathrm{v}}-A_{\mathrm{LLL}}} \\
& =\frac{1,9+14,25}{4,524-1,690-0,287} \mathrm{~m}=6,340 \mathrm{~m}
\end{aligned}
$$

\section{Duljina separatora potrebna} za izdvajanje kapljica iz plina

Vrijeme izdvajanja kapljica iz plina

$$
t_{\text {sep }}=\frac{H_{v}}{u_{\mathrm{t}}}=\frac{0,96 \mathrm{~m}}{0,726 \mathrm{~m} \mathrm{~s}^{-1}}=1,322 \mathrm{~s}
$$

Vodoravna brzina plina u parnom prostoru

$$
u_{\mathrm{G}}=\frac{Q_{\mathrm{vG}}}{A_{\mathrm{v}}}=\frac{7,361 \mathrm{~m}^{3} \mathrm{~s}^{-1}}{1,69 \mathrm{~m}^{2}}=4,357 \mathrm{~m} \mathrm{~s}^{-1}
$$

Minimalna duljina separatora potrebna za izdvajanje kapljica

$$
L_{\text {min, },}=u_{\mathrm{G}} t_{\text {sep }}=4,357 \mathrm{~m} \mathrm{~s}^{-1} \cdot 1,322 \mathrm{~s}=5,758 \mathrm{~m}
$$

\section{Kontrola duljine separatora}

Duljina separatora i potrebne duljine za separaciju i zadržaj kapljevine

\begin{tabular}{l|l}
\hline duljina separatora & $6,000 \mathrm{~m}$ \\
\hline potrebna duljina za zadržaj kapljevine & $6,340 \mathrm{~m}$ \\
\hline potrebna duljina za izdvajanje kapljica iz plina & $5,750 \mathrm{~m}$ \\
\hline
\end{tabular}

Duljina separatora dugog $6 \mathrm{~m}$ zadovoljava izdvajanje kapljica iz plina, ali je premala za potreban zadržaj kapljevine. Možemo načiniti sljedeće:

- Smanjiti visinu parnog prostora. Potrebna duljina za izdvajanje kapljica je manja od duljine separatora.

- Povećati promjer separatora. To će za istu duljinu separatora povećati volumen koji zauzima kapljevina.

- Povećati duljinu separatora na duljinu potrebnu za zadržaj kapljevine.

Za prvi pokušaj smanjimo visinu parnog prostora tako da računamo s $H_{\sqrt{ }} / D_{\mathrm{i}}=0,35$.

Ponovni proračun od točke 4 daje:

\begin{tabular}{l|l}
\hline duljina separatora & $6,000 \mathrm{~m}$ \\
\hline potrebna duljina za zadržaj kapljevine & $5,715 \mathrm{~m}$ \\
\hline potrebna duljina za izdvajanje kapljica iz plina & $6,033 \mathrm{~m}$ \\
\hline
\end{tabular}

Ponovni pokušaj s $H_{\sqrt{ }} / D_{\mathrm{i}}=0,36$ daje:

\begin{tabular}{l|l}
\hline duljina separatora & $6,000 \mathrm{~m}$ \\
\hline potrebna duljina za zadržaj kapljevine & $5,828 \mathrm{~m}$ \\
\hline potrebna duljina za izdvajanje kapljica iz plina & $5,972 \mathrm{~m}$ \\
\hline
\end{tabular}

To je rezultat koji zadovoljava.

\section{Visine nivoa u separatoru}

Visina NLL

$$
\begin{gathered}
A_{\mathrm{LLL}}=0,287 \mathrm{~m}^{2} \\
A_{\mathrm{NLL}}=A_{\mathrm{LLL}}+\frac{V_{\mathrm{h}}}{L}=0,287 \mathrm{~m}^{2}+\frac{1,9 \mathrm{~m}^{3}}{L}=0,604 \mathrm{~m}^{2} \\
X=\frac{A_{\mathrm{NLL}}}{A_{\mathrm{t}}}=\frac{0,604 \mathrm{~m}^{2}}{4,524 \mathrm{~m}^{2}}=0,133
\end{gathered}
$$

Iz korelacije u tablici 31:

$$
Y=0,191 ; \mathrm{NLL}=Y \cdot D_{\mathrm{i}}=0,191 \cdot 2,4=0,459 \mathrm{~m} .
$$

Visina HLL

$$
\mathrm{HLL}=D_{\mathrm{i}}\left(1-\frac{H_{\mathrm{v}}}{D_{\mathrm{i}}}\right)=2,4 \mathrm{~m} \cdot(1-0,36)=1,536 \mathrm{~m}
$$




\section{Priključci}

\begin{tabular}{l|c}
\hline Namjena & Nazivni promjer \\
\hline ulaz pojne smjese & 24 " Sch 10 \\
izlaz plina & 24 " Sch 10 \\
izlaz kapljevine & 4 " Sch 10
\end{tabular}

Za detalje postupka i proračun vidi Primjer 1.

\section{Dimenzije separatora}

\begin{tabular}{|c|c|}
\hline promjer & $2400 \mathrm{~mm}$ \\
\hline duljina & $6000 \mathrm{~mm}$ \\
\hline$L / D$ & 2,5 \\
\hline HLL & $1360 \mathrm{~mm}$ \\
\hline NLL & $459 \mathrm{~mm}$ \\
\hline LLL & $275 \mathrm{~mm}$ \\
\hline \multicolumn{2}{|c|}{ priključci } \\
\hline ulaz smjese & 24" Sch 10 \\
\hline izlaz plina & 24" Sch 10 \\
\hline izlaz kapljevine & 4" Sch 10 \\
\hline
\end{tabular}

\section{Pad tlaka}

\begin{tabular}{c|r}
\hline & $\Delta p / \mathrm{Pa}$ \\
\hline ulaz smjese & 1184 \\
izlaz plina & 439 \\
\hline
\end{tabular}

Za detalje postupka i proračun priključaka i pada tlaka vidi Primjer 1.

\section{Trofazni separatori}

Kao i kod dvofaznih i kod trofaznih imamo dva osnovna tipa separatora, okomiti i vodoravni. Međutim, za razliku od dvofaznih, postoji više, da ih nazovemo, podtipova trofaznih. Razlike su dosta velike i o njima će biti govora kod opisa postupka proračuna.

Izbor između okomitog i vodoravnog separatora, kao i kod dvofaznih, ovisi o omjeru plina prema kapljevini u smjesi. Kod malog protoka kapljevine u odnosu na plin $(<10-15 \%$ mase) uzima se okomiti separator.

Proračun se temelji na istim principima kao proračun dvofaznih separatora, samo je unesen dodatni kriterij, dovoljno dugo zadržavanje kapljevite faze, i lakše i teže, da se osigura željeno odvajanje tih dviju faza.

Kod okomitih trofaznih separatora upotreba pregrade ima svrhu smirivanja sekcije odvajanja kapljevina pa time potpomoganja separacije.

Kod vodoravnih trofaznih separatora razlike su u sekciji za razdvajanje kapljevina. Sekcija odvajanja kapljevina je

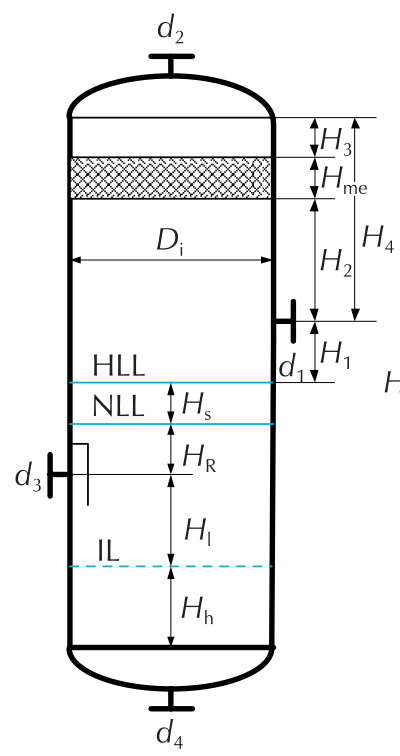

(a) konvencionalni conventional

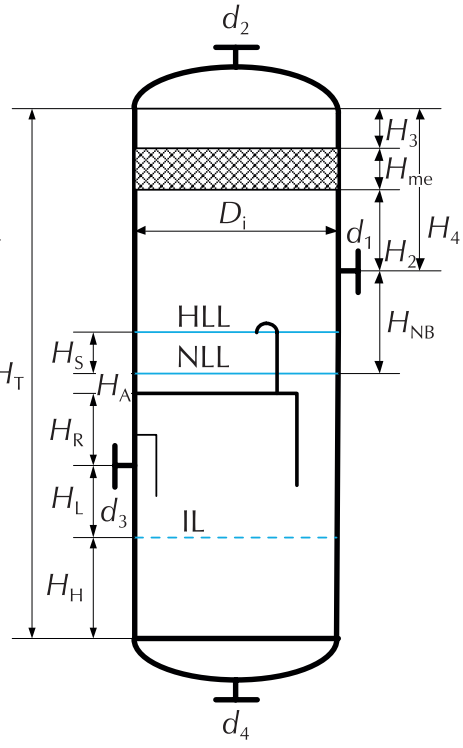

(b) s pregradom with bafle
Slika 25 - Okomiti trofazni separatori

Fig. 25 - Vetrical three-phase separators

obično varijacija načina regulacije međufaznog nivoa upotrebom slivnika ili pregrade. Slivnik se obično upotrebljava kada je protok teže kapljevine znatno manji od protoka lakše kapljevine $(<15-20 \%$ mase od ukupnog protoka kapljevine).

Izvedba s komorom i pregradom primjenjuje se kada je omjer lakše kapljevine u odnosu na težu mali, kada je teško regulirati međufazni nivo, na primjer s teškim uljima, ili kada se radi o velikim količinama emulzije ili parafina.

\section{Primjer 3. Okomiti VLL-separator (konvencionalni) Islika 25a)}

Unutarnji promjer separatora zadan je brzinom i volumnim protokom plina.

Visine sekcija u parnom prostoru iskustveni su podatci, a visine slojeva lakše i teže kapljevine računaju se na temelju vremena izdvajanja kapljica lakše kapljevine iz teže kapljevine i kapljica teže kapljevine iz lakše kapljevine. Volumen zadržavanja i poremećaja je volumen između HLL i NLL.

Ne računa se s volumenom donje podnice. Taj je volumen neka vrsta sigurnosne margine.

\section{Podatci za proračun}

Treba načiniti proračun trofaznog separatora za odvajanje plinsko-kapljevite smjese sljedećih karakteristika:

protok plina, $Q_{v G}=2500 \mathrm{~m}^{3} \mathrm{~h}^{-1}$

gustoća plina, $\rho_{\mathrm{G}}=20 \mathrm{~kg} \mathrm{~m}^{-3}$

viskoznost plina, $\mu_{\mathrm{G}}=0,01 \mathrm{mPa} \mathrm{s}$

protok lakše kapljevine, $Q_{\mathrm{vLl}}=5 \mathrm{~m}^{3} \mathrm{~h}^{-1}$ 


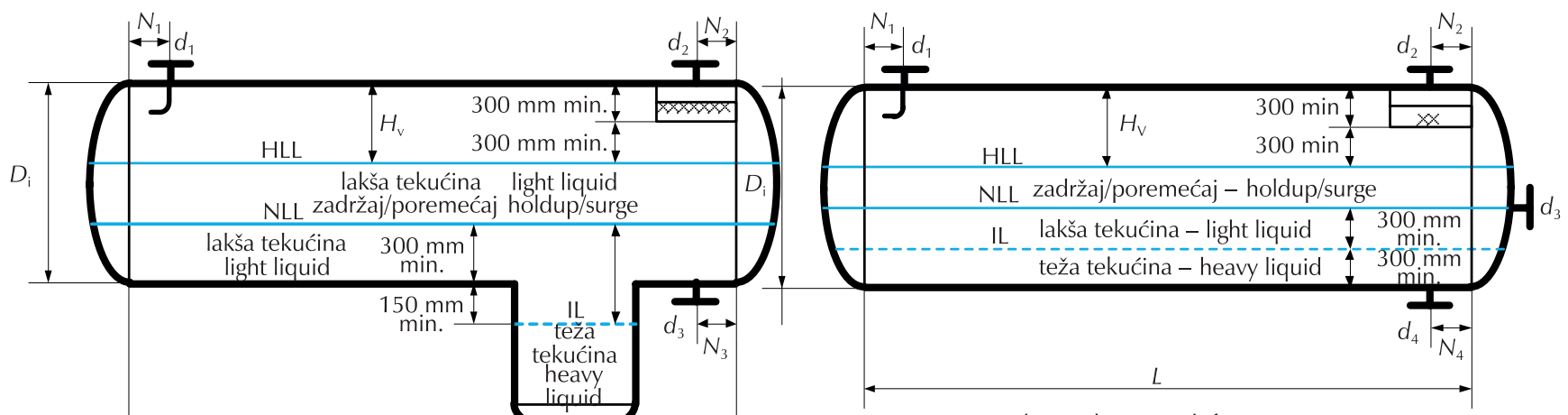

(b) regulacija međufazne razine

(b) interface control

(a) regulacija međufazne razine i slivnik

(a) interface control with boot

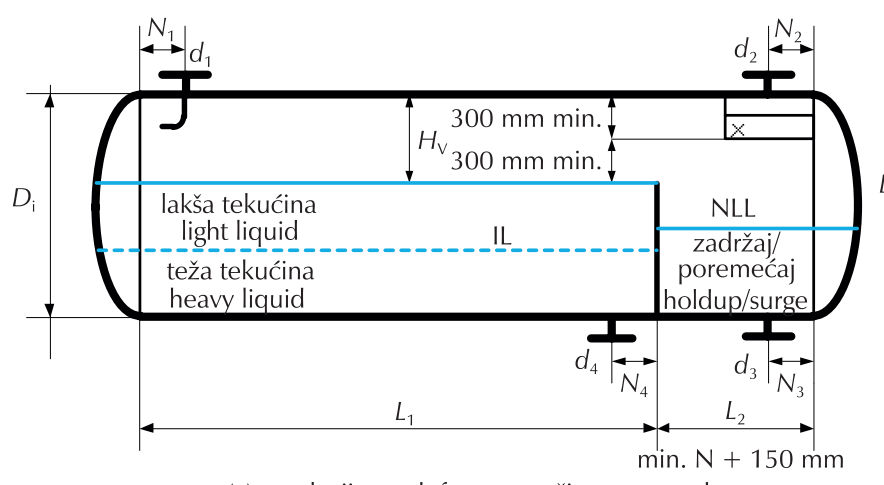

(c) regulacija međufazne površine s pregradom

(c) interface control with weir

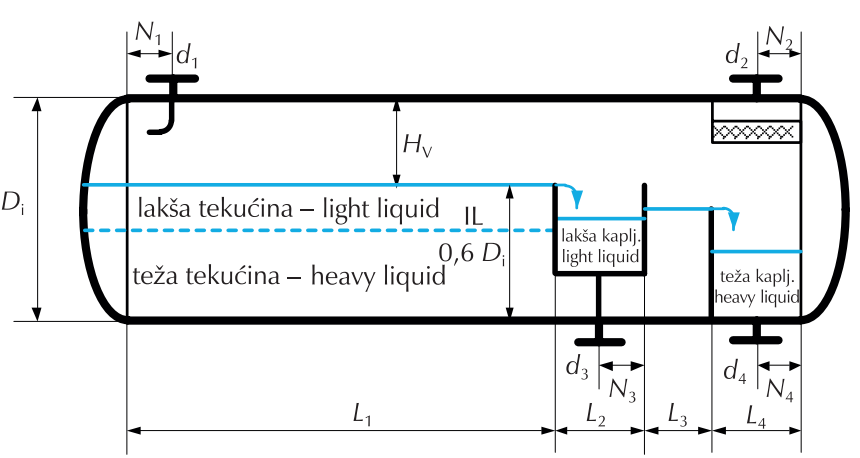

(d) komora i pregrada (d) bucket and weir

Slika 26 - Vodoravni trofazni separatori

Fig. 26 - Horizontal three phase separators

gustoća kapljevine, $\rho_{\mathrm{LI}}=865 \mathrm{~kg} \mathrm{~m}^{-3}$

viskoznost lakše kapljevine, $\mu_{\mathrm{LI}}=0,63 \mathrm{mPa} \mathrm{s}$

protok teže kapljevine, $Q_{v L h}=1 \mathrm{~m}^{3} \mathrm{~h}^{-1}$

gustoća kapljevine, $\rho_{\mathrm{Lh}}=995 \mathrm{~kg} \mathrm{~m}^{-3}$

viskoznost teže kapljevine, $\mu_{\mathrm{Lh}}=0,765 \mathrm{mPa} \mathrm{s}$

granični promjer kapljice koja se odvaja iz plina,

$D_{\mathrm{p}}=200 \mu \mathrm{m}$

radni tlak separatora, $p=10$ bar

u separator se ugrađuje odvajač kapljica

distributor ulazne smjese je deflektor

vrijeme zadržavanja, $t_{\mathrm{h}}=5 \mathrm{~min}$

vrijeme poremećaja, $t_{\mathrm{s}}=3 \mathrm{~min}$

sigurnosna margina/sigurnosni faktor, $F_{\mathrm{s}}=1,15$

\section{Souders-Brown K-faktor i granična brzina plina}

$U$ separator će biti ugrađen odvajač kapljica od čelične mrežice, pa Souders-Brownov K-faktor računamo korelacijama za odvajače iz mrežice (Koch-Otto York) za apsolutni radni tlak $p=11,013$ bar:

$$
\begin{aligned}
K & =[0,1123-0,007 \cdot \ln (p / \text { bar })] \mathrm{ms}^{-1} \\
& =(0,1123-0,007 \cdot \ln 11,013) \mathrm{ms}^{-1} \\
& =0,096 \mathrm{~ms}^{-1}
\end{aligned}
$$

Granična brzina plina iz jedn. 15 (računamo s lakšom kapljevine):

$u_{\mathrm{t}}=u_{\mathrm{d}}=K \sqrt{\frac{\rho_{\mathrm{L}}-\rho_{\mathrm{C}}}{\rho_{\mathrm{G}}}}=0,096 \mathrm{~m} \mathrm{~s}^{-1} \sqrt{\frac{865-20}{20}}=0,621 \mathrm{~m} \mathrm{~s}^{-1}$

\section{Brzine odvajanja kapljevina računamo Stokesovom korelacijom:}

$$
\begin{aligned}
u_{\mathrm{Lh}} & =g D_{\mathrm{p}}^{2} \frac{\rho_{\mathrm{p}}-\rho}{18 \mu}=9,806 \cdot\left(200 \cdot 10^{-6}\right)^{2} \frac{995-865}{18 \cdot 0,00063} \mathrm{~m} \mathrm{~s}^{-1} \\
& =0,0045 \mathrm{~m} \mathrm{~s}^{-1}=0,270 \mathrm{~m} \mathrm{~min}^{-1}
\end{aligned}
$$

To je nešto veća brzina od prihvatljive brzine izdvajanja $u_{\mathrm{Lh}, \max }=0,00425 \mathrm{~m} \mathrm{~s}^{-1}$ pa stoga u daljnjem proračunu računamo s $u_{\mathrm{Lh}}=0,00425 \mathrm{~m} \mathrm{~s}^{-1}=0,225 \mathrm{~m} \mathrm{~min}^{-1}$.

$$
\begin{aligned}
u_{\mathrm{LI}} & =g D_{\mathrm{p}}^{2} \frac{\rho_{\mathrm{p}}-\rho}{18 \mu}=9,806 \cdot\left(200 \cdot 10^{-6}\right)^{2} \frac{995-865}{18 \cdot 0,000764} \mathrm{~m} \mathrm{~s}^{-1} \\
& =0,00370 \mathrm{~m} \mathrm{~s}^{-1} \\
u_{\mathrm{LI}} & =0,222 \mathrm{~m} \mathrm{~min}^{-1}
\end{aligned}
$$




\section{Promjer separatora}

$$
D_{i}=\left(\frac{4 Q_{v G}}{\pi u_{d}}\right)^{1 / 2}=\left(\frac{4 \cdot 0,799}{\pi \cdot 0,621}\right)^{1 / 2} m=1,280 m
$$

Ako se ugrađuje odvajač kapljica, tada promjeru treba dodati širinu prstena nosača odvajača kapljica. Širina prstena $t_{\text {nok }}=50 \mathrm{~mm}$.

$$
D_{\mathrm{i}}=D_{\mathrm{i}}+2 t_{\text {nok }}=1,280 \mathrm{~m}+2 \cdot 0,05 \mathrm{~m}=1,380 \mathrm{~m}
$$

Nema potrebe za zaokruživanjem:

$$
D_{\mathrm{i}}=1,380 \mathrm{~m}=1380 \mathrm{~mm}
$$

Površina presjeka:

$$
A_{\mathrm{t}}=\frac{D_{\mathrm{i}}^{2} \cdot \pi}{4}=\frac{(1,380 \mathrm{~m})^{2} \cdot \pi}{4}=1,496 \mathrm{~m}^{2}
$$

\section{Visine sloja lakše i teže kapljevine}

Minimalne visine $H_{\mathrm{LI}}$ i $H_{\mathrm{Lh}}$ su:

$$
H_{\mathrm{LI}}=300 \mathrm{~mm} ; H_{\mathrm{Lh}}=300 \mathrm{~mm}
$$

Te visine uzimamo za prvi pokušaj.

Potrebno vrijeme za izdvajanje kapljica lakše kapljevine iz teže i teže kapljevine iz lakše

$$
\begin{aligned}
& t_{\text {sep }, \mathrm{Lh}}=\frac{H_{\mathrm{LI}}}{u_{\mathrm{Lh}}}=\frac{0,3 \mathrm{~m}}{0,00425 \mathrm{~m} \mathrm{~s}^{-1}}=70,6 \mathrm{~s} \\
& t_{\text {sep }, \mathrm{LI}}=\frac{H_{\mathrm{Lh}}}{u_{\mathrm{Ll}}}=\frac{0,3 \mathrm{~m}}{0,00370 \mathrm{~m} \mathrm{~s}^{-1}}=81,0 \mathrm{~s}
\end{aligned}
$$

Vrijeme zadržavanja lakše i teže kapljevine

$$
\begin{aligned}
t_{\mathrm{hLh}} & =\frac{H_{\mathrm{Lh}} A}{Q_{\mathrm{vLh}}}=\frac{0,3 \mathrm{~m} \cdot 1,496 \mathrm{~m}^{2}}{0,000315 \mathrm{~m}^{3} \mathrm{~s}^{-1}}=1404,7 \mathrm{~s} \\
t_{\mathrm{hLI}} & =\frac{H_{\mathrm{LI}} A}{Q_{\mathrm{vLI}}}=\frac{0,3 \mathrm{~m} \cdot 1,496 \mathrm{~m}^{2}}{0,00160 \mathrm{~m}^{3} \mathrm{~s}^{-1}}=280,9 \mathrm{~s}
\end{aligned}
$$

Vremena zadržavanja lakše i teže kapljevine u separatoru veća su od vremena potrebnih za odvajanje kapljevine.

U slučaju da su vremena zadržavanja manja od potrebnih vremena razdvajanje, može se ili povećati promjer separatora ili povećati visine slojeva $H_{\mathrm{Ll}} \mathrm{i} H_{\mathrm{Lh}}$.

\section{Visine $H_{\mathrm{R}} i H_{\mathrm{s}}$}

$H_{R}$ je visina lakše kapljevine iznad osi izlaznog priključka i računa se iz vremena zadržavanja lakše kapljevine:

$$
H_{\mathrm{R}}=\frac{Q_{\mathrm{VL} \mid} \mathrm{t}_{\mathrm{h}}}{A_{\mathrm{t}}}=\frac{0,00160 \mathrm{~m}^{3} \mathrm{~s}^{-1} \cdot 5 \cdot 60 \mathrm{~s}}{1,496 \mathrm{~m}^{2}}=0,321 \mathrm{~m}
$$

Zaokružimo na $H_{\mathrm{R}}=0,320 \mathrm{~m}$.
$H_{\mathrm{s}}$ je visina iznad NLL predviđena za kompenzaciju poremećaja (HLL):

$$
\begin{aligned}
H_{s} & =\frac{\left(Q_{\mathrm{vLL}}+Q_{\mathrm{vLh}}\right) t_{\mathrm{s}}}{A_{\mathrm{t}}} \\
& =\frac{(0,00160+0,000319) \mathrm{m}^{3} \mathrm{~s}^{-1} \cdot 3 \cdot 60 \mathrm{~s}}{1,496 \mathrm{~m}^{2}}=0,231 \mathrm{~m}
\end{aligned}
$$

zaokružimo na $H_{\mathrm{s}}=0,230 \mathrm{~m}$

\section{Priključci}

\begin{tabular}{c|c}
\hline ulaz pojne smjese & $12^{\text {" Sch } 10}$ \\
\hline vanjski promjer & $323 \mathrm{~mm}$ \\
\hline izlaz plina & $12^{\prime \prime}$ Sch 10 \\
\hline izlaz lakše kapljevine & $2^{\text {" Sch } 10}$ \\
\hline izlaz teže & 2" Sch 10 \\
\hline
\end{tabular}

Za detalje postupka i proračun vidi Primjer 1.

\section{Visine parnog prostora}

Prema tablici 20 visine parnog prostora za okomiti separator s odvajačem kapljica i raspodjelnikom u obliku poluotvorene cijevi su:

\begin{tabular}{c|c|c|c|c}
\hline $\begin{array}{c}\text { Tip } \\
\text { raspodjelnika }\end{array}$ & $H_{1}$ & $H_{2}$ & $H_{3}$ & $\begin{array}{c}\text { Visina } \\
\text { raspodjelnika }\end{array}$ \\
\hline $\begin{array}{c}0,3 D_{\mathrm{i}} \\
\text { poluotvorena } \\
\text { cijev }\end{array}$ & $\begin{array}{c}0,45 D_{\mathrm{i}} \\
\text { min. }\end{array}$ & $\begin{array}{c}\text { min. } \\
0,15 D_{\mathrm{i}}\end{array}$ & $\begin{array}{c}\text { min. } \\
600 \mathrm{~mm}\end{array}$ & $\mathrm{~d}_{1}$ \\
\hline
\end{tabular}

Promjer separatora $D_{\mathrm{i}}=1380 \mathrm{~mm}$, unutarnji promjer priključka za ulaz pojne smjese $d_{1}=315 \mathrm{~mm}$. Prema tome:

$$
\begin{aligned}
& H_{1}=0,3 \times 1380 \mathrm{~mm}=414 \mathrm{~mm}, \\
& \text { zaokruženo } H_{1}=415 \mathrm{~mm} \\
& H_{2}=0,45 \times 1380 \mathrm{~mm}=621 \mathrm{~mm}, \\
& \text { zaokruženo } H_{2}=620 \mathrm{~mm} \\
& H_{3}=0,15 \times 1380 \mathrm{~mm}=207 \mathrm{~mm}, \\
& \text { zaokruženo } H_{3}=210 \mathrm{~mm}
\end{aligned}
$$

\section{Dimenzije separatora (za oznake vidi sliku 24(a))}

\begin{tabular}{lr}
\hline promjer & $1380 \mathrm{~mm}$ \\
duljina & $2638 \mathrm{~mm}$ \\
$H / D$ & 1,72 \\
$H_{1}$ & $415 \mathrm{~mm}$ \\
$H_{2}$ & $620 \mathrm{~mm}$ \\
$H_{\text {me }}$ & $150 \mathrm{~mm}$ \\
$H_{3}$ & $210 \mathrm{~mm}$ \\
$d_{1}$ & $323 \mathrm{~mm}$ \\
$H_{\mathrm{h}}$ & $300 \mathrm{~mm}$
\end{tabular}




\begin{tabular}{lc}
\hline$H_{\mathrm{I}}$ & $300 \mathrm{~mm}$ \\
$H_{\mathrm{R}}$ & $320 \mathrm{~mm}$ \\
$H_{\mathrm{s}}$ & $230 \mathrm{~mm}$ \\
$\mathrm{HLL}$ & $830 \mathrm{~mm}$ \\
$\mathrm{NLL}$ & $600 \mathrm{~mm}$ \\
$\mathrm{IL}$ & $300 \mathrm{~mm}$ \\
\hline & \\
\hline ulaz smjese & priključci \\
izlaz plina & $12^{\prime \prime}$ \\
izlaz lakše kapljevine & $12^{\prime \prime}$ \\
izlaz teže kapljevine & $2^{\prime \prime}$ \\
\hline
\end{tabular}

\section{Pad tlaka}

\begin{tabular}{l|c}
\hline ulaz smjese & $1334 \mathrm{~Pa}$ \\
\hline izlaz plina & $529 \mathrm{~Pa}$ \\
\hline žičana mrežica, $1 \mathrm{~m}^{2}$ & $383 \mathrm{~Pa}$ \\
\hline & $44 \mathrm{~mm}$ stupca kapljevine \\
\hline- dvostruki džepovi & $128 \mathrm{~Pa}$ \\
\hline
\end{tabular}

Za detalje postupka i proračun vidi Primjer 1.

\section{Primjer 4. Okomiti VLL-separator (s pregradom) (slika 25b)}

Proračun je sličan proračunu za separator bez pregrade. Upotreba pregrade poboljšava rad separatora jer smiruje prostor separacije.

Proračun je radi usporedbe načinjen za istu trofaznu smjesu kao i prethodni proračun konvencionalnog separatora.

\section{Podatci za proračun}

Treba načiniti proračun trofaznog separatora za odvajanje plinsko-kapljevite smjese sljedećih karakteristika:

protok plina, $Q_{v G}=2500 \mathrm{~m}^{3} \mathrm{~h}^{-1}$

gustoća plina, $\rho_{\mathrm{G}}=20 \mathrm{~kg} \mathrm{~m}^{-3}$

viskoznost plina, $\mu_{\mathrm{G}}=0,01 \mathrm{mPa} \mathrm{s}$

protok lakše kapljevine, $Q_{\mathrm{vL}}=5 \mathrm{~m}^{3} \mathrm{~h}^{-1}$

gustoća kapljevine, $\rho_{\mathrm{LI}}=865 \mathrm{~kg} \mathrm{~m}^{-3}$

viskoznost lakše kapljevine, $\mu_{\mathrm{LI}}=0,63 \mathrm{mPa} \mathrm{s}$

protok teže kapljevine, $Q_{v L h}=1 \mathrm{~m}^{3} \mathrm{~h}^{-1}$

gustoća kapljevine, $\rho_{\mathrm{Lh}}=995 \mathrm{~kg} \mathrm{~m}^{-3}$

viskoznost teže kapljevine, $\mu_{\mathrm{Lh}}=0,765 \mathrm{mPa} \mathrm{s}$

granični promjer kapljice koja se odvaja iz plina, $D_{\mathrm{p}}=200 \mathrm{~mm}$

radni tlak separatora, $p=10$ bar

u separator se ugrađuje odvajač kapljica

distributor ulazne smjese je deflektor

vrijeme zadržavanja, $t_{\mathrm{h}}=5 \mathrm{~min}$ vrijeme poremećaja, $t_{\mathrm{s}}=3 \mathrm{~min}$

sigurnosna margina/sigurnosni faktor, $F_{\mathrm{s}}=1,15$

\section{Souders-Brownov K-faktor i granična brzina plina}

U separator će biti ugrađen odvajač kapljica od čelične mrežice pa Souders-Brownov $K$-faktor računamo korelacijama za odvajače iz mrežice (Koch-Otto York) za apsolutni radni tlak $p=11,013$ bar:

$$
\begin{aligned}
K & =[0,1123-0,007 \cdot \ln (p / \text { bar })] \mathrm{ms}^{-1} \\
& =(0,1123-0,007 \cdot \ln 11,013) \mathrm{ms}^{-1} \\
& =0,096 \mathrm{~m} \mathrm{~s}^{-1}
\end{aligned}
$$

Granična brzina plina iz jed. 15 (računamo s lakšom kapljevinom):

$$
\begin{aligned}
u_{\mathrm{t}}=u_{\mathrm{d}} & =K \sqrt{\frac{\rho_{\mathrm{L}}-\rho_{\mathrm{G}}}{\rho_{\mathrm{G}}}}=0,096 \mathrm{~m} \mathrm{~s}^{-1} \sqrt{\frac{865-20}{20}} \\
& =0,621 \mathrm{~m} \mathrm{~s}^{-1}
\end{aligned}
$$

\section{Brzine odvajanja kapljevina računamo} Stokesovom korelacijom:

$$
\begin{aligned}
u_{\text {Lh }} & =g D_{\mathrm{p}}^{2} \frac{\rho_{\mathrm{p}}-\rho}{18 \mu}=9,806 \cdot\left(200 \cdot 10^{-6}\right)^{2} \frac{995-865}{18 \cdot 0,00063} \mathrm{~m} \mathrm{~s}^{-1} \\
& =0,00425 \mathrm{~m} \mathrm{~s}^{-1}
\end{aligned}
$$

To je točno na granici maksimalne brzine odvajanja.

$$
\begin{aligned}
u_{\mathrm{LI}} & =g D_{\mathrm{p}}^{2} \frac{\rho_{\mathrm{p}}-\rho}{18 \mu}=9,806 \cdot\left(200 \cdot 10^{-6}\right)^{2} \frac{995-865}{18 \cdot 0,000764} \mathrm{~m} \mathrm{~s}^{-1} \\
& =0,00370 \mathrm{~m} \mathrm{~s}^{-1}
\end{aligned}
$$

\section{Promjer separatora}

$$
D_{\mathrm{i}}=\left(\frac{4 Q_{\mathrm{vG}}}{\pi u_{\mathrm{d}}}\right)^{1 / 2}=\left(\frac{4 \cdot 0,799}{\pi \cdot 0,621}\right)^{1 / 2} \mathrm{~m}=1,280 \mathrm{~m}
$$

Ako se ugrađuje odvajač kapljica, tada promjeru treba dodati širinu prstena nosača odvajača kapljica. Širina prstena $t_{\text {nok }}=50 \mathrm{~mm}$

$$
\begin{aligned}
D_{\mathrm{i}} & =D_{\mathrm{i}}+2 t_{\text {nok }}=1,280 \mathrm{~m}+2 \cdot 0,05 \mathrm{~m} \\
& =1,380 \mathrm{~m}
\end{aligned}
$$

Nema potrebe za zaokruživanjem:

$$
D_{\mathrm{i}}=1,380 \mathrm{~m}=1380 \mathrm{~mm}
$$

Površina presjeka:

$$
A_{\mathrm{t}}=\frac{D_{\mathrm{i}}^{2} \cdot \pi}{4}=\frac{(1,380 \mathrm{~m})^{2} \cdot \pi}{4}=1,496 \mathrm{~m}^{2}
$$


4. Visine sloja lakše i teže kapljevine

$$
H_{\mathrm{Ll}}=300 \mathrm{~mm} ; H_{\mathrm{Lh}}=300 \mathrm{~mm}
$$

To su minimalne visine i uzimamo ih za prvi pokušaj.

\section{Potrebno vrijeme za izdvajanje kapljica lakše} kapljevine iz teže i teže kapljevine iz lakše

$$
\begin{aligned}
& t_{\text {sep }, \mathrm{Lh}}=\frac{H_{\mathrm{LI}}}{u_{\mathrm{Lh}}}=\frac{0,3 \mathrm{~m}}{0,00425 \mathrm{~m} \mathrm{~s}^{-1}}=70,6 \mathrm{~s} \\
& t_{\text {sep }, \mathrm{LI}}=\frac{H_{\mathrm{Lh}}}{u_{\mathrm{Ll}}}=\frac{0,3 \mathrm{~m}}{0,00370 \mathrm{~m} \mathrm{~s}^{-1}}=81,0 \mathrm{~s}
\end{aligned}
$$

\section{Površina pregrade}

Ovdje se proračun razlikuje od proračuna konvencionalnog separatora. Vrijeme zadržavanja lakše kapljevine računamo s površinom pregrade. To je površina presjeka separatora umanjena za površinu preljeva. Pretpostavimo $H_{\mathrm{R}}=0,3 \mathrm{~m}$ (minimum).

$$
H_{\mathrm{R}}+H_{1}=0,3+0,3=0,6 \mathrm{~m}
$$

Srednja gustoća kapljevine:

$$
\begin{aligned}
\rho_{\mathrm{ML}} & =\frac{Q_{\mathrm{vLh}} \rho_{\mathrm{Lh}}+Q_{\mathrm{vLL}} \rho_{\mathrm{LL}}}{Q_{\mathrm{vLh}}+Q_{\mathrm{vL}}} \\
& =\frac{0,000277 \cdot 995+0,00139 \cdot 865}{0,000277+0,00139} \mathrm{~kg} \mathrm{~m}^{-3} \\
& =866,7 \mathrm{~kg} \mathrm{~m}^{-3}
\end{aligned}
$$

Razlika gustoća plina i kapljevine:

$$
\Delta \rho=866,7 \mathrm{kgm}^{-3}-20,0 \mathrm{kgm}^{-3}=846,7 \mathrm{kgm}^{-3}
$$

Iz slike 27 maksimalni dopušteni protok kroz preljev $q_{\mathrm{pr}}=394 \mathrm{~m}^{3} \mathrm{~h}^{-1} \mathrm{~m}^{-2}$

Površina preljeva:

$$
\begin{aligned}
A_{\mathrm{pr}} & =\frac{Q_{\mathrm{vLh}}+Q_{\mathrm{vLL}}}{q_{\mathrm{pr}}}=\frac{(0,000319+0,00160) \mathrm{m}^{3} \mathrm{~s}^{-1}}{(394 / 3600) \mathrm{m}^{3} \mathrm{~s}^{-1} \mathrm{~m}^{-2}} \\
& =0,0170 \mathrm{~m}^{2}
\end{aligned}
$$

Uz: $A_{\mathrm{p}} / A_{\mathrm{t}}=0,017$ i korelacije za površinu i visinu kružnog odsječka visina preljeva:

$$
Y=0,03315 \text { i } H_{\mathrm{pr}}=0,0458 \mathrm{~m}
$$

Uzimamo $H_{\mathrm{pr}}=0,1 \mathrm{~m}$ i iz omjera $H_{\mathrm{pr}} / D_{\mathrm{i}}$ računamo novu površinu preljeva $A_{\mathrm{pr}}=0,188 \mathrm{~m}^{2}$.

Površina pregrade je:

$$
A_{\mathrm{prg}}=A_{\mathrm{t}}-A_{\mathrm{pr}}=1,496 \mathrm{~m}^{2}-0,188 \mathrm{~m}^{2}=1,307 \mathrm{~m}^{2} .
$$

To je površina s kojom ćemo računati vrijeme zadržavanja lakše kapljevine.

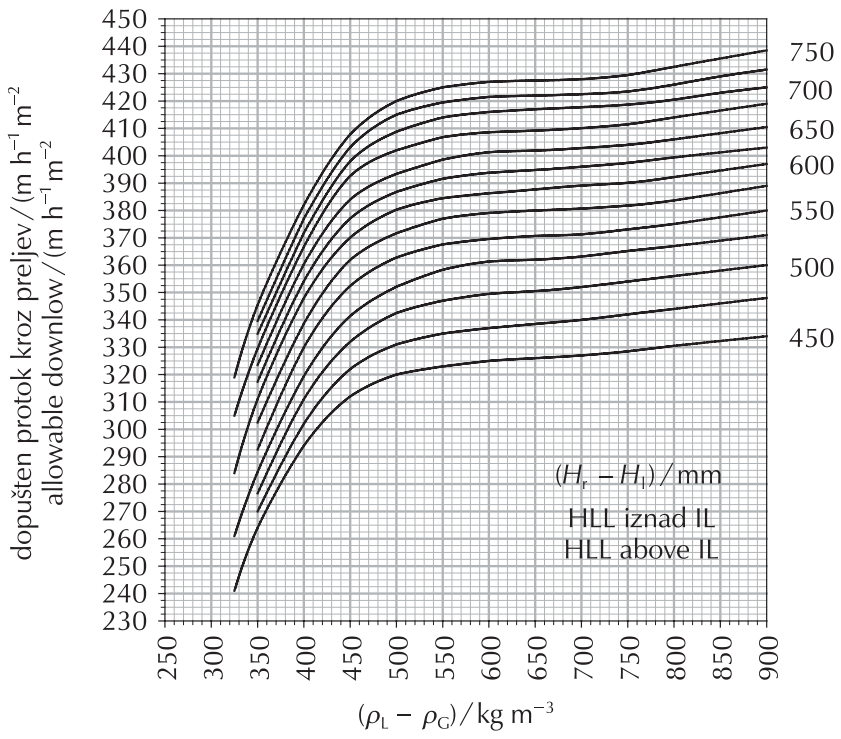

Slika 27 - Dopušten protok kroz preliv

Fig. 27 -Downcomer allowable flow

\section{Vrijeme zadržavanja lakše i teže kapljevine}

$$
\begin{gathered}
t_{\mathrm{hLh}}=\frac{H_{\mathrm{Lh}} A_{\mathrm{Lh}}}{Q_{\mathrm{vLh}}}=\frac{0,3 \mathrm{~m} \cdot 1,496 \mathrm{~m}^{2}}{0,000319 \mathrm{~m}^{3} \mathrm{~s}^{-1}}=1405 \mathrm{~s} \\
t_{\mathrm{hLh}}=23,4 \mathrm{~min} \\
t_{\mathrm{hLI}}=\frac{H_{\mathrm{LI}} A_{\mathrm{LL}}}{Q_{\mathrm{vLL}}}=\frac{0,3 \mathrm{~m} \cdot 1,307 \mathrm{~m}^{2}}{0,00160 \mathrm{~m}^{3} \mathrm{~s}^{-1}}=246 \mathrm{~s} \\
t_{\mathrm{hL}}=4,1 \mathrm{~min}
\end{gathered}
$$

\begin{tabular}{l|c|cc}
\hline & $\begin{array}{c}\text { Vrijeme } \\
\text { zadržavanja/s }\end{array}$ & Potrebno vrijeme izdvajanja/s \\
\hline lakša kapljevina & 246 & Lh iz LI & 70,6 \\
teža kapljevina & 1405 & LI iz Lh & 81
\end{tabular}

Vremena zadržavanja lakše i teže kapljevine u separatoru veća su od vremena potrebnih za odvajanje kapljevina.

U slučaju da su vremena zadržavanja manja od potrebnih vremena razdvajanje, može se ili povećati promjer separatora ili povećati visine slojeva $H_{1}$ i $H_{\mathrm{h}}$ i ponoviti proračun. 


\section{Priključci}

\begin{tabular}{l|c}
\hline Namjena & Nazivni promjer \\
\hline ulaz pojne smjese & 12 " Sch 10 \\
vanjski promjer & $323 \mathrm{~mm}$ \\
izlaz plina & 12 " Sch 10 \\
izlaz lakše kapljevine & 2" Sch 10 \\
izlaz teže kapljevine & 2" Sch 10 \\
\hline
\end{tabular}

Za detalje postupka i proračun vidi Primjer 1.

\section{Visine $H_{\mathrm{R}}, H_{\mathrm{S}}, H_{\mathrm{NB}}$ i $H_{\mathrm{A}}$}

$H_{R}$ je visina lakše kapljevine iznad osi izlaznog priključka do pregrade temeljena na zadanom vremenu zadržavanja:

$$
H_{\mathrm{R}}=\frac{Q_{\mathrm{vLI}} t_{\mathrm{h}}}{A_{\mathrm{pr}}}=\frac{0,0016 \mathrm{~m}^{3} \mathrm{~s}^{-1} \cdot 5 \cdot 60 \mathrm{~s}}{1,307 \mathrm{~m}^{2}}=0,366 \mathrm{~m}
$$

Zaokružimo na $H_{\mathrm{R}}=0,370 \mathrm{~m}$

$H_{\mathrm{A}}$ - visina kapljevine iznad pregrade (NLL) uzimamo $H_{\mathrm{A}}=0,05 \mathrm{~m}$.

$H_{\mathrm{s}}$ je visina iznad NLL predviđena za kompenzaciju poremećaja (HLL):

$$
\begin{aligned}
H_{s} & =\frac{\left(Q_{\mathrm{vLL}}+Q_{\mathrm{vLh}}\right) t_{\mathrm{s}}}{A_{\mathrm{t}}} \\
& =\frac{(0,00160+0,000319) \mathrm{m}^{3} \mathrm{~s}^{-1} \cdot 3 \cdot 60 \mathrm{~s}}{1,496 \mathrm{~m}^{2}}=0,230 \mathrm{~m}
\end{aligned}
$$

Minimum je 150 mm, stoga rezultat zadovoljava.

$H_{\mathrm{NB}}$ je visina od NLL do osi priključka za ulaz pojne smjese i jednaka većoj vrijednosti od:

$$
\begin{aligned}
& H_{\mathrm{NB}}=0,6 \mathrm{~m}+0,5 d_{1}=0,6 \mathrm{~m}+0,5 \cdot 0,315 \mathrm{~m} \\
& =0,7575 \mathrm{~m}
\end{aligned}
$$

ili

$$
\begin{aligned}
& H_{\mathrm{NB}}=H_{\mathrm{s}}+0,15 \mathrm{~m}+0,5 \mathrm{~d}_{1} \\
& =0,230 \mathrm{~m}+0,15 \mathrm{~m}+0,5 \cdot 0,315 \mathrm{~m}=0,5375 \mathrm{~m}
\end{aligned}
$$

Uzimamo $H_{\mathrm{NB}}=0,7575 \mathrm{~m}$ i zaokružimo na $H_{\mathrm{NB}}=0,760 \mathrm{~m}$

\section{Visine parnog prostora}

Prema tablici 20 visine parnog prostora za okomiti separator s odvajačem kapljica i raspodjelnikom u obliku poluotvorene cijevi su:

\begin{tabular}{c|c|c|c|c}
\hline $\begin{array}{c}\text { Tip } \\
\text { raspodjelnika }\end{array}$ & $H_{1}$ & $H_{2}$ & $H_{3}$ & $\begin{array}{c}\text { Visina } \\
\text { raspodjelnika }\end{array}$ \\
\hline $\begin{array}{c}\text { poluotvorena } \\
\text { cijev }\end{array}$ & $\begin{array}{c}0,3 D_{\mathrm{i}} \\
\mathrm{min} .\end{array}$ & $\begin{array}{c}0,45 D_{\mathrm{i}} \\
\mathrm{min} .\end{array}$ & $\begin{array}{c}0,5 D_{\mathrm{i}} \\
\text { min. }\end{array}$ & $\mathrm{d}_{1}$ \\
\hline
\end{tabular}

$$
\begin{aligned}
& D_{\mathrm{i}}=1380 \mathrm{~mm} ; d_{1}=323 \mathrm{~mm} \\
& H_{2}=0,45 \times 1380 \mathrm{~mm}=621 \mathrm{~mm}, \\
& \text { zaokruženo } H_{2}=620 \mathrm{~mm} \\
& H_{3}=0,15 \times 1380=207 \mathrm{~mm}, \\
& \text { zaokruženo } H_{3}=210 \mathrm{~mm}
\end{aligned}
$$

\section{Pad tlaka}

Protoci i dimenzije priključaka su identični kao i u primjeru za konvencionalni separator, pa su i padovi tlaka isti:

\begin{tabular}{l|c}
\hline ulaz smjese & $1334 \mathrm{~Pa}$ \\
\hline izlaz plina & $529 \mathrm{~Pa}$ \\
\hline žičana mrežica $\left(1 \mathrm{~m}^{2}\right)$ & $383 \mathrm{~Pa}$ \\
\hline & $44 \mathrm{~mm}$ stupca kapljevine \\
\hline & $128 \mathrm{~Pa}$ \\
\hline
\end{tabular}

Za detalje postupka i proračun vidi Primjer 1.

\section{Rekapitulacija dimenzija}

\begin{tabular}{lr}
\hline promjer & $1380 \mathrm{~mm}$ \\
visina & $2760 \mathrm{~mm}$ \\
$H / D$ & 2,0 \\
$H_{\mathrm{NB}}$ & $760 \mathrm{~mm}$ \\
$H_{2}$ & $620 \mathrm{~mm}$ \\
$H_{\mathrm{me}}$ & $150 \mathrm{~mm}$ \\
$H_{3}$ & $210 \mathrm{~mm}$ \\
$d_{1}$ & $323 \mathrm{~mm}$ \\
$H_{\mathrm{A}}$ & $50 \mathrm{~mm}$ \\
$H_{\mathrm{R}}$ & $370 \mathrm{~mm}$ \\
$H_{\mathrm{L}}$ & $300 \mathrm{~mm}$ \\
$H_{\mathrm{H}}$ & $300 \mathrm{~mm}$ \\
$H_{\mathrm{S}}$ & $230 \mathrm{~mm}$ \\
HLL & $1250 \mathrm{~mm}$ \\
NLL & $1020 \mathrm{~mm}$ \\
IL & $300 \mathrm{~mm}$ \\
\hline & \\
\hline ulaz smjese & $12^{\prime \prime}$ \\
izlaz plina & $12^{\prime \prime}$ \\
izlaz lakše kapljevine & 2 priključci \\
\hline
\end{tabular}




\section{Popis kratica i simbola List of abbreviations and symbols}

A $\quad$ - površina, $\mathrm{m}^{2}$

- area, $\mathrm{m}^{2}$

$A_{\mathrm{h}} \quad$ - površina presjeka volumena zadržaja kod vodoravnog separatora, $\mathrm{m}^{2}$

- hold up volume cross-section area in horizontal separator, $\mathrm{m}^{2}$

$A_{\mathrm{LLL}} \quad$ - površina presjeka koji zauzima kapljevina do niskog nivoa, $\mathrm{m}^{2}$

- liquid cross-section area at low level, $\mathrm{m}^{2}$

$A_{\mathrm{Lh}} \quad$ - površina presjeka volumena zadržaja teže kapljevine, $\mathrm{m}^{2}$

- hold up volume cross-section area of heavy liquid, $\mathrm{m}^{2}$

$A_{\mathrm{LI}} \quad$ - površina presjeka volumena zadržaja lakše kapljevine, $\mathrm{m}^{2}$

- hold up volume cross-section area of light liquid, $\mathrm{m}^{2}$

$A_{\mathrm{NLL}}$ - površina presjeka separatora do normalne visine kapljevine, $\mathrm{m}^{2}$

- cross-section separator area up to normal liquid level, $\mathrm{m}^{2}$

$A_{\mathrm{pr}} \quad$ - površina preljeva, $\mathrm{m}^{2}$

- overflow area, $\mathrm{m}^{2}$

$A_{s, m e}$ - površina presjeka žičane mrežice okomito na tok plina, $\mathrm{m}^{2}$

- mist separator surface area perpendicular to gas flow, $\mathrm{m}^{2}$

$A_{\mathrm{s}} \quad$ - površina presjeka volumena poremećaja kod

vodoravnog separatora, $\mathrm{m}^{2}$

- surge volume cross-section area in horizontal separator, $\mathrm{m}^{2}$

$A_{\mathrm{t}} \quad$ - površina presjeka separatora, $\mathrm{m}^{2}$

- separator cross-section area, $\mathrm{m}^{2}$

$A_{v} \quad$ - površina presjeka parnog prostora kod vodoravnog separatora, $\mathrm{m}^{2}$

- vapour space cross-section area in horizontal separator, $\mathrm{m}^{2}$

$C_{D} \quad$ - koeficijent trenja

- drag coefficient

D - promjer, $\mathrm{m}$

- diameter, $m$

$D_{\mathrm{i}} \quad$ - unutarnji promjer separatora, $\mathrm{m}, \mathrm{mm}$

- separator inner diameter, $\mathrm{m}, \mathrm{mm}$

$D_{\mathrm{p}} \quad$ - promjer kapi, $\mathrm{mm}$

- drop diameter, $\mathrm{mm}$

$d_{1} \quad$ - unutarnji promjer priključka za pojenje, $\mathrm{mm}$

- feed nozzle inner diameter, mm

$d_{2} \quad$ - unutarnji promjer priključka za izlaz plina, $\mathrm{mm}$

- gas outlet nozzle inner diameter, mm

$d_{3} \quad$ - unutarnji promjer priključka za izlaz kapljevine

VL-separatora, $\mathrm{mm}$

- liquid outlet nozzle inner diameter in VL separator, $\mathrm{mm}$

- unutarnji promjer priključka za izlaz lakše kapljevine

VLL-separatora, $\mathrm{mm}$

- light liquid outlet nozzle inner diameter in VLL separator, $\mathrm{mm}$

$d_{4} \quad$ - unutarnji promjer priključka za izlaz teže kapljevine

VLL-separatora, $\mathrm{mm}$

- heavy liquid outlet nozzle inner diameter in VLL separator, $\mathrm{mm}$

$d_{\mathrm{i}} \quad$ - unutarnji promjer cijevi, $\mathrm{mm}$

- pipe inner diameter, $\mathrm{mm}$

$d_{\text {o }} \quad$ - vanjski promjer cijevi, $\mathrm{mm}$

- pipe outer diameter, $\mathrm{mm}$

$\mathrm{Fr}_{\mathrm{G}} \quad$ - Froudeova značajka za plin

- gas Froude number

$F r_{L} \quad$ - Froudeova značajka za kapljevinu

- liquid Froude number
$F_{\mathrm{s}} \quad$ - sigurnosni faktor

- safety factor

g - gravitacijsko ubrzanje, $g=9,806 \mathrm{~m} \mathrm{~s}^{-2}$

- gravitational acceleration

H - visina, $\mathrm{m}$

- height, $\mathrm{m}$

$H_{1} \quad$ - visina parnog prostora između HLL i simetrale ulaznog priključka (okomiti separator), $\mathrm{mm}$

- vapour space height from HLL to inlet nozzle center line (vertical separator), $\mathrm{mm}$

$H_{2}$ - visina parnog prostora od simetrale ulaznog priključka do donjeg ruba odvajača kapljica (okomiti separator), $\mathrm{mm}$

- vapour space height from inlet nozzle center line to the edge of mist separator (vertical separator), $\mathrm{mm}$

$H_{3}$ - visina parnog prostora od gornjeg ruba odvajača kapljica do gornje T/L (okomiti separator), mm

- vapour space height from top edge of mist separator to top $\mathrm{T} / \mathrm{L}$ (vertical separator), $\mathrm{mm}$

$H_{4}$ - visina parnog prostora od HLL do gornje T/L (okomiti separator), $\mathrm{mm}$

- vapour space height from HLL to top T/L (vertical separator), $\mathrm{mm}$

$H_{\mathrm{A}} \quad$ - visina sloja kapljevine na pregradi, $\mathrm{m}$

- liquid layer height on weir, $m$

$H_{\mathrm{h}} \quad$ - visina volumena zadržavanja, $\mathrm{m}$

- hold up volume height, $\mathrm{m}$

$H_{1} \quad$ - visina od međufaznog nivoa do osi priključka za odvod lakše kapljevine, m

- height from interface level to light liquid outlet nozzle centre line, $m$

$H_{\mathrm{Lh}} \quad$ - visina sloja teže kapljevine, $\mathrm{m}$

- height of heavy liquid layer, $\mathrm{m}$

$H_{\mathrm{LI}} \quad$ - visina sloja lakše kapljevine, $\mathrm{m}$

- height of light liquid layer, $m$

$H_{\text {me }}$ - visina žičane mrežice, $\mathrm{mm}$

- mist separator height, $\mathrm{mm}$

$H_{\mathrm{NB}}$ - visina od NLL do osi priključka na ulaz smjese, $\mathrm{m}$

- height from NLL to feed nozzle centre line, $m$

$H_{\text {pr }} \quad$ - visina preljeva, $\mathrm{m}$

- overflow height, $m$

$H_{\mathrm{R}} \quad$ - visina od osi priključka za odvod lakše kapljevine do pregrade, $m$

- height from light liquid outlet nozzle centre line to weir, $m$

$H_{\mathrm{s}} \quad$ - visina volumena poremećaja, m

- surge volume height, $\mathrm{m}$

$H_{\mathrm{v}} \quad$ - visina parnog prostora (vodoravni separator), $\mathrm{m}$

- vapour space height (horizontal separator), $\mathrm{m}$

HLL - visoki nivo kapljevine, $\mathrm{m}$

- high liquid level, m

K - Souders-Brownov faktor, $K$-faktor, $\mathrm{ms}^{-1}$

- Souders-Brown factor, $K$-factor, $\mathrm{ms}^{-1}$

$K_{v} \quad$ - faktor pada tlaka u pločastom odvajaču kapljica (jedn. 26)

- pressure drop factor in vane demister (eq. 26)

IL $\quad$ - međufazni nivo

- interface level

L - duljina, $m$

- length, m

$L_{\mathrm{H} / \mathrm{S}} \quad$ - duljina separatora koja zadovoljava vremena zadržaja i poremećaja, $m$

- separator length that meets hold up time and feed surge time, $\mathrm{m}$ 
$L_{\min , \mathrm{G}}-$ minimalna duljina vodoravnog separatora za odvajanje kapljica iz plina, $\mathrm{m}$

- minimum horizontal separator length, $\mathrm{m}$

LLL - niski nivo kapljevine, $\mathrm{m}$

- low liquid level, m

NLL - normalni nivo kapljevine, $m$

- normal liquid level, $\mathrm{m}$

p - tlak, bar

- pressure, bar

$\Delta p \quad$ - pad tlaka, Pa

- pressure drop, Pa

$Q_{v G} \quad$ - volumni protok plina, $\mathrm{m}^{3} \mathrm{~h}^{-1}, \mathrm{~m}^{3} \mathrm{~s}^{-1}$

- gas volume flux, $\mathrm{m}^{3} \mathrm{~h}^{-1}, \mathrm{~m}^{3} \mathrm{~s}^{-1}$

$Q_{v L} \quad$ - volumni protok kapljevine, $\mathrm{m}^{3} \mathrm{~h}^{-1}, \mathrm{~m}^{3} \mathrm{~s}^{-1}$

- liquid volume flux, $\mathrm{m}^{3} \mathrm{~h}^{-1}, \mathrm{~m}^{3} \mathrm{~s}^{-1}$

$Q_{v L h}$ - volumni protok teže kapljevine, $\mathrm{m}^{3} \mathrm{~h}^{-1}, \mathrm{~m}^{3} \mathrm{~s}^{-1}$

- heavy liquid volume flux, $\mathrm{m}^{3} \mathrm{~h}^{-1}, \mathrm{~m}^{3} \mathrm{~s}^{-1}$

$Q_{\mathrm{vLI}}$ - volumni protok lakše kapljevine, $\mathrm{m}^{3} \mathrm{~h}^{-1}, \mathrm{~m}^{3} \mathrm{~s}^{-1}$

- light liquid volume flux, $\mathrm{m}^{3} \mathrm{~h}^{-1}, \mathrm{~m}^{3} \mathrm{~s}^{-1}$

$Q_{v M}$ - volumni protok dvofazne/trofazne smjese, $\mathrm{m}^{3} \mathrm{~h}^{-1}$

- multiphase mixture volume flux, $\mathrm{m}^{3} \mathrm{~h}^{-1}$

$q_{\mathrm{pr}} \quad$ - gustoća volumnog toka kroz preljev, $\mathrm{m}^{3} \mathrm{~h}^{-1} \mathrm{~m}^{-2}$

- volume flux density through overflow, $\mathrm{m}^{3} \mathrm{~h}^{-1} \mathrm{~m}^{-2}$

Re - Reynoldsova značajka

- Reynolds number

T/L - tangentna linija podnice posude

- bottom tangent line

$t_{\mathrm{h}} \quad$ - vrijeme zadržavanja kapljevine u separatoru, min, $\mathrm{s}$

- hold up time, min, s

$t_{\text {hLh }}$ - vrijeme zadržavanja teže kapljevine u separatoru, $\mathrm{s}$

- heavy liquid holdup time, s

$t_{\mathrm{hLI}} \quad$ - vrijeme zadržavanja lakše kapljevine u separatoru, s

- light liquid holdup time, s

$t_{\mathrm{me}} \quad$ - debljina sloja žičane mrežice, $\mathrm{m}$

- wire mesh demister pad thickness, $m$

$t_{\text {nok }} \quad$ - širina prstena nosača odvajača kapljica, $m, \mathrm{~mm}$

- width of mist eliminator support ring, $\mathrm{m}, \mathrm{mm}$

$t_{\mathrm{s}} \quad$ - vrijeme poremećaja protoka, $\min , \mathrm{s}$

- feed surge time, min, $\mathrm{s}$

$t_{\text {sep }} \quad$ - vrijeme odvajanja dviju kapljevitih faza, s

- liquid phase separation time, s

$t_{\text {sep,Lh }}$ - vrijeme potrebno za izdvajanje kapljica teže kapljevine iz lakše, s

- heavy liquid dropout time, s $t_{\text {sep,Ll }}$ - vrijeme potrebno za izdvajanje kapljica lakše kapljevine iz teže, s

- light liquid dropout time, $\mathrm{s}$

u $\quad$ - brzina, $\mathrm{m} \mathrm{min}^{-1}, \mathrm{~ms}^{-1}$

- velocity, $\mathrm{m} \mathrm{min}^{-1}, \mathrm{~ms}^{-1}$

$u_{\mathrm{d}} \quad$ - projektna brzina plina kroz odvajač kapljica, $\mathrm{m} \mathrm{s}^{-1}$

- gas velocity through mist eliminator, $\mathrm{ms}^{-1}$

$u_{\mathrm{G}} \quad$ - brzina plina, $\mathrm{ms}^{-1}$

- gas velocity, $\mathrm{ms}^{-1}$

$u_{\mathrm{Lh}} \quad$ - brzina izdvajanja kapljica teže kapljevine iz lakše, $\mathrm{ms}^{-1}$

- heavy liquid dropout velocity, $\mathrm{ms}^{-1}$

$u_{\mathrm{LI}} \quad$ - brzina izdvajanja kapljica lakše kapljevine iz teže, $\mathrm{ms}^{-1}$

- light liquid dropout velocity, $\mathrm{m} \mathrm{s}^{-1}$

$u_{\mathrm{M}} \quad$ - brzina dvofazne/trofazne smjese, $\mathrm{ms}^{-1}$

- multiphase mixture flow velocity, $\mathrm{ms}^{-1}$

$u_{\mathrm{t}} \quad$ - granična brzina kontinuirane faze, $\mathrm{ms}^{-1}$

- terminal velocity of contimuous phase, $\mathrm{ms}^{-1}$

$V_{\mathrm{h}} \quad$ - volumen zadržavanja kapljevine, $\mathrm{m}^{3}$

- liquid hold up volume, $\mathrm{m}^{3}$

$V_{\mathrm{s}} \quad$ - volumen poremećaja, $\mathrm{m}^{3}$

- surge volume, $\mathrm{m}^{3}$

VL - dvofazna smjesa plin/kapljevina

- two-phase mixture gas/liquid

VLL - trofazna smjesa plin/kapljevina/kapljevina

- three-phase mixture gas/liquid/liquid

$\lambda$ - faktor opterećenja mrežice plinom, $\mathrm{ms}^{-1}$

- gas loading factor, $\mathrm{m} \mathrm{s}^{-1}$

$\mu_{\mathrm{C}} \quad-$ viskoznost plina, $\mathrm{mPa}$

- gas viscosity, mPas

$\mu_{\mathrm{Lh}} \quad$ - viskoznost teže kapljevine, mPas

- heavy liquid viscosity, mPas

$\mu_{\mathrm{LI}} \quad$ - viskoznost lakše kapljevine, mPas

- light liquid viscosity, mPa s

$\rho_{\mathrm{G}} \quad$ - gustoća plina, $\mathrm{kg} \mathrm{m}^{-3}$

- gas density, $\mathrm{kg} \mathrm{m}^{-3}$

$\rho_{\mathrm{L}} \quad$ - gustoća kapljevine, $\mathrm{kg} \mathrm{m}^{-3}$

- liquid density, $\mathrm{kg} \mathrm{m}^{-3}$

$\rho_{\mathrm{Lh}} \quad-$ gustoća teže kapljevine, $\mathrm{kg} \mathrm{m}^{-3}$

- heavy liquid density, $\mathrm{kg} \mathrm{m}^{-3}$

$\rho_{\mathrm{LI}} \quad$ - gustoća lakše kapljevine, $\mathrm{kg} \mathrm{m}^{-3}$

- light liquid density, $\mathrm{kg} \mathrm{m}^{-3}$

$\rho_{\mathrm{M}} \quad$ - gustoća dvofazne/trofazne smjese, $\mathrm{kg} \mathrm{m}^{-3}$

- multiphase mixture density, $\mathrm{kgm}^{-3}$ 


\section{Literatura}

\section{References}

1. D. W. Green, R. H. Perry (ur.), Perry's Chemical Engineers' Handbook 8. izd., McGraw-Hill, New York, 2008.

2. API Standard 521 Pressure-Relieving and Depressuring Systems.

3. W. L. McCabe, J. C. Smith, Unit Operations of Chemical Engineering, 3. izd., McGraw-Hill, New York, 1976.

4. F. H. Wu, Drum separator design. A new approach, Chem. Eng. 91 (7) (1984) 74.

5. A. H. Selker, C. A. Sleicher, Factors affecting which phase will disperse when immiscible liquids are stirred together, Can. J. Chem. Eng. 43 (1965) 298, doi: http://dx.doi.org/10.1002/ cjce. 5450430606 .

6. Gas/liquid separators - Type selection and design rules, Shell GSI, 2007.

7. S. Rahimi, Three phase separators - Inlet devices, URL: http://chemwork.org/PDF/board/Three\%20phase\%20Separator\%20-\%20Inlet\%20Devices.pdf.

8. S. A. Ziebold, Demystifying mist eliminator selection, Chem. Eng. 107 (5) (2000) 94.

9. M. Bothamley, Gas/Liquids Separators - Part 2, Quantifying Separation Performance, Oil and Gas Facilities 2 (5) (2013) 35.

10. C. L. Carpenter, D. F. Othmer, Entrainment removal by a wire-mesh separator, AIChE J. 1 (4) (1955) 549, doi: http:// dx.doi.org/10.1002/aic.690010428.

11. J. P. Monat, K. J. McNulty, I. S. Michelson, O. V. Hansen, Accurate evaluation of chevron mist eliminators, Chem. Eng. Progr. 82 (1986) 32.

12. API specification 12J. Specification for Oil and Gas Separators.
13. GPSA Engineering Data Book, 10. izd. 1987, Vol. 1, Chapter 7: Separators. Gas Processors and Suppliers Association, Tulsa.

14. Process design of gas(vapour)-liquid separators (Project standard and specifications), Rev. 01, KLM Technology Group, Johor Bahru, 2011.

15. F. Boukadi, V. Singh, R. Trabelsi, F. Sebring, D. Allen, V. Pai, Appropriate separator sizing: A modified Stewart and Arnold method, Model. Simulat. Eng. 2012 (2012) Article ID 721814, doi: http://dx.doi.org/10.1155/2012/721814.

16. NORSOK Standard P-100, Process systems, Rev 2, Norwegian Technology Centre, Oslo, 2001.

17. P. Fabian, R. Cusack, P. Hennessey, N. Neuman, Demystifying the selection of mist eliminators. Part 1, Chem. Eng. 100 (11) (1993) 148-156.

18. W. D. Monnery,W. Y. Svrcek, Successfully specify three-phase separators, Chem. Eng. Prog. 90 (9) (1994) 29-40.

19. W. Y. Svrcek, W. D. Monnery, Design two-phase separators within the right limits, Chem. Eng. Prog. 80 (1993) 53.

20. S. Rahimi, Three phase separators - Gas internals, URL: http://www.chemwork.org/PDF/board/Three\%20phase\%20 Separator\%20-\%20Gas\%20Internals.pdf.

21. S. Rahimi, Three phase separators - Times definition, URL: http://www.chemwork.org/PDF/board/Three\%20Phase\%20 Separators\%20-\%20Times\%20Definition.pdf.

22. R. N. Watkins, Sizing separators and accumulators, Hydrocarbon Process. 46 (11) (1967) 253-256.

23. A. Gerunda, How to Size Liquid-Vapor Separators, Chem. Eng. 88 (9) (1981) 81-84.

24. H. Sarma, How to Size Gas Scrubber, Hydrocarbon Process. 69 (1981) 251-255.

25. P. G. Talavera, Selecting Gas/Liquid Separators, Hydrocarbon Process. 69 (6) (1990) 81-84.

\section{SUMMARY \\ Gravity Vapour/Liquid Separators. Part III. \\ Eduard Beer}

Not many papers report about the sizing procedures for gravity separators, but those that do usually include data for basic types of vapour/liquid separators. Sizing procedures for specific types regularly contain data based on experience, which is why companies are reluctant to publish them. This paper presents the design procedures for eight types of gravity separators, together with examples for easier comprehension.

\section{Keywords}

Gravity separator, gas/liquid separator, gas/liquid/liquid separator, design procedures

Aleja Blaža Jurišića 9

10000 Zagreb
Professional paper

Received January 5, 2015 Accepted December 7, 2015 